\title{
Measurement Signal Quality Assessment on All Available and New Signals of Multi-GNSS (GPS, GLONASS, Galileo, BDS, and QZSS) with Real Data
}

\author{
Yiming Quan ${ }^{1}$, Lawrence Lau ${ }^{2}$, Gethin W. Roberts ${ }^{2}$ and Xiaolin Meng ${ }^{3}$ \\ ${ }^{1}$ (International Doctoral Innovation Centre, University of Nottingham Ningbo China) \\ ${ }^{2}$ (University of Nottingham Ningbo China) \\ ${ }^{3}$ (University of Nottingham, $U K$ ) \\ (E-mail: yiming.quan@nottingham.edu.cn)
}

\begin{abstract}
Global Navigation Satellite Systems (GNSS) Carrier Phase (CP)-based high-precision positioning techniques have been widely used in geodesy, attitude determination, engineering survey and agricultural applications. With the modernisation of GNSS, multi-constellation and multi-frequency data processing is one of the foci of current GNSS research. The GNSS development authorities have better designs for the new signals, which are aimed for fast acquisition for civil users, less susceptible to interference and multipath, and having lower measurement noise. However, how good are the new signals in practice? The aim of this paper is to provide an early assessment of the newly available signals as well as assessment of the other currently available signals. The signal quality of the multi-GNSS (GPS, GLONASS, Galileo, BDS and QZSS) is assessed by looking at their zero-baseline Double Difference (DD) CP residuals. The impacts of multi-GNSS multi-frequency signals on single-epoch positioning are investigated in terms of accuracy, precision and fixed solution availability with known short baselines.
\end{abstract}

\section{KEYWORDS

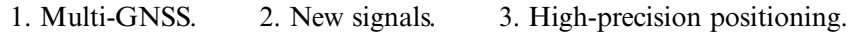

Submitted: 29 December 2014. Accepted: 24 July 2015. First published online: 4 September 2015.

1. INTRODUCTION. Currently, the US Global Positioning System (GPS) and the Russian Global Navigation Satellite System (GLONASS) are the only two fully operational satellite positioning systems with global coverage. GPS uses Code Division Multiple Access (CDMA) techniques to differentiate the satellites. All the blocks of GPS satellites (i.e., Blocks IIA, IIR, IIR-M, and IIF) transmit at least two types of ranging codes: the Coarse/Acquisition (C/A) codes and the Precise (P) code. The C/A code is open to civilian users, and the $\mathrm{P}$ code is only available to military 
and authorised users through encryption into the Y-code. However, the $\mathrm{P}(\mathrm{Y})$ codes can still be tracked using special tracking techniques such as cross-correlation or Z-tracking (Ashjaee and Lorenz, 1992; Seeber, 2003. P.240-243). GLONASS mainly uses Frequency Division Multiple Access (FDMA) techniques to distinguish the satellites. Similar to GPS, GLONASS also has standard accuracy signals L1OF and L2OF open to the public and high accuracy signals L1SF and L2SF reserved for military (Russian Institute of Space Device Engineering, 2008).

With the modernisation of GNSS, multi-constellation and multi-frequency data processing are the foci of current GNSS research. GPS Block IIR-M satellites transmit the new L2C signal, which can enhance the use of L2 in high-precision applications. Moreover, a new civil signal L5 on a third carrier frequency band is being transmitted on the Block IIF satellites. The L5 signal is expected to improve the precision and robustness of the system, supporting 'Safety of Life' applications. Another new civil signal, L1C, will be available on the next-generation Block III satellites. GLONASS has started to use CDMA signals on the new GLONASS-K satellites to increase compatibility and interoperability with GPS and other GNSS systems. The European GNSS, Galileo, completed its experimental phase in 2008 and the In-Orbit Validation (IOV) phase in 2012. Galileo currently has four operational satellites in orbit and early services with reduced performance have been available since 2014 . To date China has launched 17 satellites for the BeiDou Navigation Satellite System (BDS), which includes six Geosynchronous Earth Orbit (GEO) satellites, six Medium Earth Orbit (MEO) satellites, and five Inclined Geosynchronous Satellite Orbit (IGSO) satellites. BDS B1I and B2I signals are now available to the public, and the B2I signal will be gradually replaced by a better signal in the future (China Satellite Navigation Office, 2013). Japan launched one Quasi-Zenith Satellite System (QZSS) satellite 'MICHIBIKI' in 2010. It transmits almost the same signals as the GPS Block III satellites.

With the progress of GNSS modernisation, extensive research has been conducted to investigate the performance of multi-GNSS in terms of signal and measurement quality, positioning accuracy and precision, and positioning availability. After the launch of the first Block IIF satellite, Montenbruck et al. (2012) reported its periodic inter-frequency clock variations, and proposed an empirical model to mitigate the variations with an accuracy of $1 \mathrm{~cm}$. De Bakker et al. (2012) analysed the Galileo E1B, and E5aQ signals; their results show the standard deviations of their DD CP measurements with zero and short baselines vary between $0.4 \mathrm{~mm}$ and $0.7 \mathrm{~mm}$. While the authors also demonstrate mixed GPS-Galileo DD Ambiguity Resolution (AR), the positioning quality is not presented, possibly due to the insufficient number of Galileo satellites at that time. Later, Steigenberger et al. (2013) showed Galileo positioning results with short baselines $(19 \mathrm{~m}$ and $101 \mathrm{~m})$. The results show the accuracy of CP positioning using four Galileo IOV satellites are from about $1 \mathrm{~cm}$ to $5 \mathrm{~cm}$. In terms of BDS and QZSS, Montenbruck et al. (2013) assessed the signal and measurement quality of regional BDS and QZSS satellites. The results show the IGSO CP noise and multipath errors are from $1 \mathrm{~mm}$ to $3 \mathrm{~mm}$ when the satellite is over about $45^{\circ}$ elevation. Shi et al. (2013) also report similar results in a short baseline (436 m) test, and the global BDS satellites are also not included in these assessments due to the insufficient BDS MEO satellites at that time. Combined GPS and BDS dual-frequency positioning results show that the combined system can improve the fixed solution precisions by more than 20\% for GPS (Odolinski et al., 2014; Shi et al, 2013). Wang 
et al. (2012) use 3D city models to assess satellite visibility in an urban canyon environment. They predict that adding Galileo and BDS to GPS and GLONASS can improve the navigation reliability at most of the simulated city locations, and the availability (of more than four satellites) can reach $100 \%$ by 2020 at those locations. Lau et al. (2015) have carried out a case study on the impacts of multi-GNSS (GPS, GLONASS, and QZSS) on positioning accuracy and multipath errors in high-precision single-epoch solutions. The results show the impact of combining GNSS systems is not always beneficial compared with GPS-only solutions. Lau et al. (2015) show this is due to the introduction of more multipath errors in their selected difficult environments.

The number of visible satellites and new signals are increasing. They provide users with more observations, and hence increase redundancy in parameter estimation. When so many satellites and signals are available, surveyors and other high-precision GNSS users may not have a clear idea about what GNSS constellations or their combinations can be optimally used, what the corresponding achievable accuracy and precision would be, and if more systems/signals can always bring about improved results. Therefore, it is important to investigate the performance of multi-GNSS (GPS, GLONASS, Galileo, QZSS, and regional and global BDS) on a wider range of new signals (assessment on GPS L2C and L5 is not found in the literature) for positioning, especially in the signal domain.

This paper carries out an early assessment to perceive the impact of multi-GNSS (GPS, GLONASS, Galileo, BDS, and QZSS) on high-precision CP-based positioning with the following objectives:

- To study the effect of measurement noise levels in all currently available signals by investigating their DD CP residuals (Test 1).

- To evaluate positioning precision, accuracy, and fixed solution availability using the selected individual GNSS constellations and their selected combinations in good and realistic environments, i.e. low multipath (Test 2) and severe multipath environments (Test 3).

2. DESCRIPTION OF TESTS AND METHODOLOGIES. All the tests were carried out in Ningbo, China. Ningbo is located in a good GNSS area, where access to the signals from multiple constellations including GPS, GLONASS, Galileo, QZSS, and regional and global BDS is available. Three tests were carried out with zero, $10 \mathrm{~m}$, and $7 \mathrm{~km}$ baselines as listed in Table 1 . Tests 1 and 2 were conducted on known points for 24 hours, with two multi-GNSS receivers continuously operating and logging the raw observation data. All the receivers in Test 1 were connected to a Leica AR20 choke-ring antenna located on the North Pillar on the roof of the University of Nottingham Ningbo China (UNNC) Science and Engineering Building (SEB) via a GEMS GS18 signal splitter. In Test 2, two Javad receivers were connected to two Leica AR20 choke-ring antennas on the North Pillar and the South Pillar on the roof of the SEB building, respectively. Since the Javad Triumph receivers were not available on 2 February 2014 (this date is chosen because four Galileo satellites could be simultaneously observed), Javad Sigma receivers were used instead to collect data. The North Pillar was used as a reference station in Test 3 , and the rover station was set on the roof of another building with a baseline length of about $7 \mathrm{~km}$. The reason to choose this baseline length is that short baselines of several kilometre length are usually used in RTK surveying. 
Table 1. List of relative positioning tests.

\begin{tabular}{|c|c|c|c|c|c|}
\hline Tests & $\begin{array}{l}\text { Baseline } \\
\text { length }\end{array}$ & $\begin{array}{l}\text { Date and time of data } \\
\text { collection (GPS time) }\end{array}$ & $\begin{array}{l}\text { Observation } \\
\text { period }\end{array}$ & Receivers used & Data-sets \\
\hline Test 1 & $0 \mathrm{~m}$ & $\begin{array}{l}\text { 14-Jun-2014 0:0:00-23:59:59 } \\
\text { 23-Jul-2014 0:0:00-23:59:59 }\end{array}$ & $24 \mathrm{~h}$ & $\begin{array}{l}\text { Javad Triumph-VS } \times 2 \\
\text { Javad Triumph-VS } \times 2 \\
\text { Septentrio NV } \times 2\end{array}$ & $\begin{array}{l}\mathrm{A} \\
\mathrm{B}\end{array}$ \\
\hline Test 2 & $10 \cdot 48 \mathrm{~m}$ & $\begin{array}{l}\text { 2-Feb-2014 0:0:00-23:59:59 } \\
\text { 17-Oct-2014 0:0:00-23:59:59 }\end{array}$ & $24 \mathrm{~h}$ & $\begin{array}{l}\text { Javad Sigma } \times 2 \\
\text { Javad Triumph-VS } \times 2\end{array}$ & $\begin{array}{l}\mathrm{C} \\
\mathrm{D}\end{array}$ \\
\hline Test 3 & $7073 \cdot 2 \mathrm{~m}$ & 26-Jul-2014 10:27:07-14:56:05 & $4 \cdot 48 \mathrm{~h}$ & $\begin{array}{l}\text { Javad Triumph-VS } \times 2 \\
\text { Septentrio NV } \times 2\end{array}$ & $\mathrm{E}$ \\
\hline
\end{tabular}

The CP residuals in Test 1 are obtained with the DD method. A single difference (SD) operation is performed for satellite $\mathrm{p}$ and receiver $\mathrm{a}$ and $\mathrm{b}$ by:

$$
\varphi_{a b}^{p}=\frac{1}{\lambda_{p}} \rho_{a b}^{p}+\frac{c}{\lambda_{p}} d t_{a b}+N_{a b}^{p}+\varepsilon_{a b}^{p}
$$

where $\varphi_{a b}^{p}$ is the SD CP, $\lambda_{p}$ is the signal wavelength of satellite $\mathrm{p}, \rho_{a b}^{p}$ is the SD range between satellite and receivers, $\mathrm{c}$ is the speed of light, $d t_{a b}$ is the SD receiver clock error, $N_{a b}^{p}$ is the SD integer ambiguity, and $\varepsilon_{a b}^{p}$ is the SD residual term. Then the $\mathrm{DD}$ operation is conducted for satellites $\mathrm{p}$ and $\mathrm{q}$ :

$$
\varphi_{a b}^{p q}=\frac{1}{\lambda_{p}} \rho_{a b}^{p}-\frac{1}{\lambda_{q}} \rho_{a b}^{q}+\left(\frac{c}{\lambda_{p}}-\frac{c}{\lambda_{q}}\right) d t_{a b}+N_{a b}^{p q}+\varepsilon_{a b}^{p q}
$$

Since the baseline length is zero, all orbit errors, multipath effects, ionospheric and tropospheric biases can be eliminated, and $\frac{1}{\lambda_{p}} \rho_{a b}^{p}-\frac{1}{\lambda_{q}} \rho_{a b}^{q}$ is zero. The DD ambiguity, $N_{a b}^{p q}$, can be easily eliminated as well since it is an integer. The reference satellite $\mathrm{p}$ is defined by one satellite with the highest elevation angle at every epoch (the GPS satellites are chosen as the reference satellites when processing using the QZSS satellite because they have similar signal structure). For GPS and the other CDMA GNSS systems with the same wavelengths, the receiver clock error can be eliminated. The DD CP becomes:

$$
\varphi_{a b}^{p q}=\varepsilon_{a b}^{p q}
$$

Therefore, the noise level of the CP measurement can be described by the DD CP residuals $\varepsilon_{a b}^{p q}$.

For GLONASS FDMA signals, the receiver clock error cannot be eliminated by the classical DD technique due to the different frequencies (and hence wavelengths) used for individual satellites. According to the method used by Wang (2000) and Ong et al. (2009), the strategy is to scale the SD CP into distances before DD operation:

$$
\phi_{a b}^{p q}=\lambda_{p} \varphi_{a b}^{p}-\lambda_{q} \varphi_{a b}^{q}=\lambda_{q} N_{a b}^{p q}+\left(\lambda_{p}-\lambda_{q}\right) N_{a b}^{p}+\bar{\varepsilon}_{a b}^{p q}
$$

where DD ambiguity $N_{a b}^{p q}$ and SD ambiguity $N_{a b}^{p}$ are all integers, and $\bar{\varepsilon}_{a b}^{p q}=\lambda_{p} \varepsilon_{a b}^{p}-\lambda_{q} \varepsilon_{a b}^{q}$ (in metres). Two receivers $a$ and $b$ used in the tests are from the same manufacturer (either Javad or Septentrio). 
All the data in Tests 2 and 3 are post-processed using RTKLIB (version 2.4.2) in kinematic single-epoch mode. All available signals assessed in Test 1 are used for data processing in Tests 2 and 3,100\% fixed positioning solutions are used to calculate the precision and accuracy. RTKLIB is open source software for GNSS data processing and analysis. Its functionalities include a precise positioning algorithm using GPS, GLONASS, Galileo, BDS, QZSS, and Satellite-Based Augmentation Systems (SBAS) (Takasu, 2013). In data processing, RTKLIB scales CP observations into distance, so that GLONASS receiver clock errors can be estimated. This is a common method for GLONASS AR. Another method is to estimate receiver clock errors from SD code pseudoranges (Takac, 2009). Before DD is formed, RTKLIB selects a reference satellite with the highest elevation angle at each epoch, and no DD operation is performed between different systems except between GPS and QZSS. The data is processed with a combination of forward and reverse solutions (Kalman filter smoothing), with the elevation mask set at $15^{\circ}$. The ambiguity is resolved by LAMBDA (Least Squares Ambiguity Decorrelation Adjustment) and its extended MLAMBDA (Modified LAMBDA) method (Takasu, 2013; Teunissen, 1993, 1995). As the rover is stationary, the correctness of AR is validated by the final positioning solution. If the $3 \mathrm{D}$ residual error of a DD measurement of an epoch is greater than half of the observing wavelength, then it is considered as the wrong AR. The use of reverse solutions can increase the number of epochs with correct AR, so that more samples for signal quality assessment are available. Since the position of the rover station in Test 3 is unknown, its position was determined by static survey and post processing.

\section{RESULTS}

3.1. Zero-baseline test (Test 1) results. The DD CP residuals of some selected satellites of multi-GNSS (GPS, GLONASS, Galileo, BDS, and QZSS) for all available real signals from data collected are shown in Figures 1 to 4 . The criterion of selection is to choose satellites with as many observations as possible. In Figure 1, the top five plots show the DD CP residuals of satellite PRN30 with all GPS signals and their frequency histograms. The last plot shows the elevation angles of satellite PRN30 and its reference satellites (there are some overlapping lines but easy to recognise). In Figures 1 and 5 there are more than one reference satellite during some epochs. This is because for L2C and L5 signals transmitted by GPS satellite Blocks IIR-M (L2C), IIF (L2C and L5), and the QZSS satellite, the reference satellites are selected from the same blocks to compute residuals. Though the new L2C and L5 signals are currently available, they are still in a pre-operational state (National Coordination Office for Space-Based Positioning, Navigation, and Timing, 2014), and signal interruption occurred during the tests (for example in Figure 1, there is no L2C from satellite PRN30 after epoch about 288,000 ).

From Figures 1 to 5, it can be seen that all the DD CP residuals follow statistical normal distributions. Also, the standard deviations of the residuals increase with the decrease in satellite elevation angle, especially for GPS P(Y) signals. As stated in Section 2, the reference satellite in DD is the highest elevation satellite at each epoch, so there are no DDs for one satellite if the highest elevation satellite is itself. This situation can be seen in Figure 1 for L5 residual after about epoch 312,500, and the gaps in Figures 2, 4, and 5. 


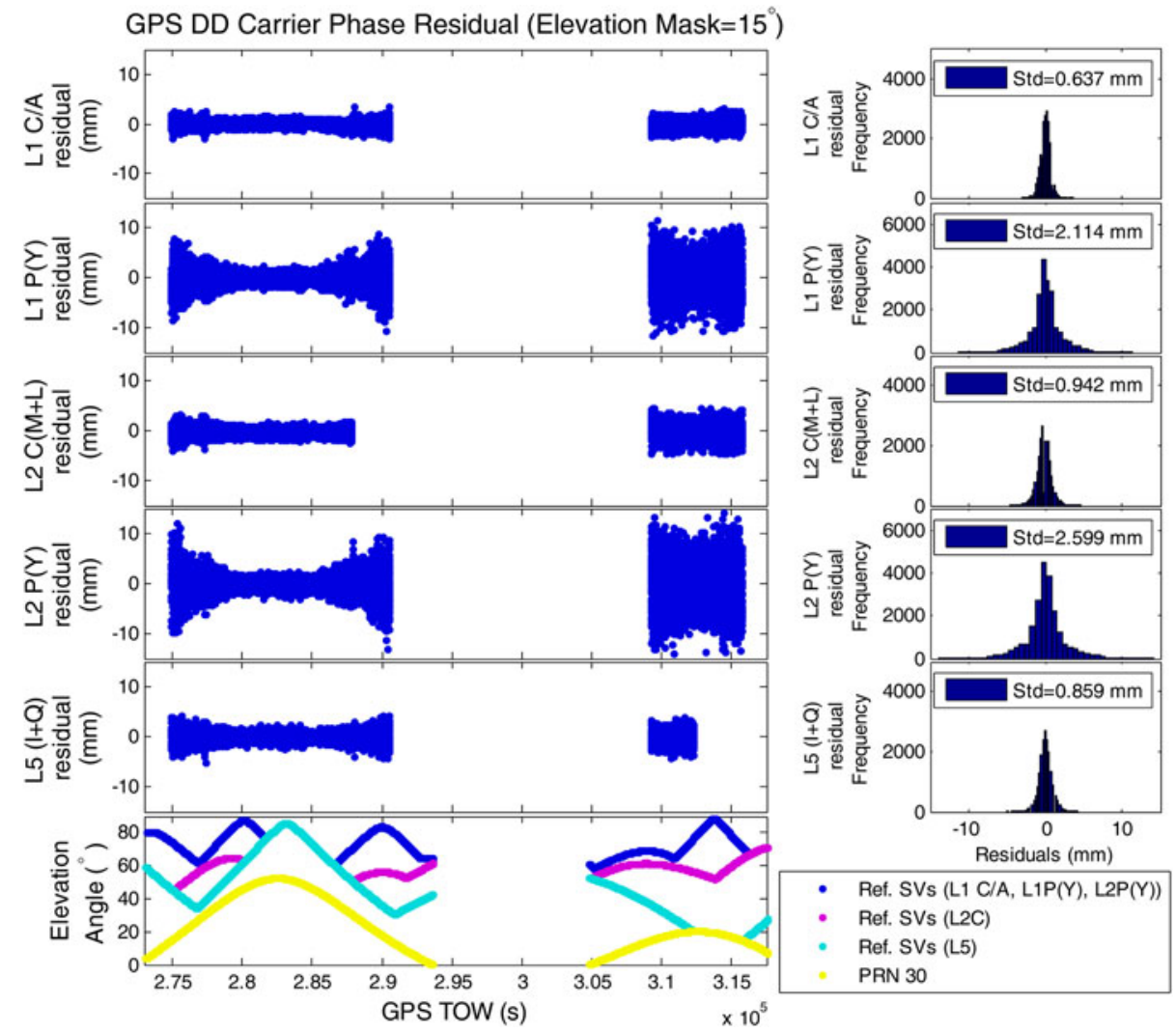

Figure 1. GPS DD CP residual for PRN30 in Test 1.

The standard deviations of residuals in all signals, modulations and the number of available satellites, are summarised in Table 2. Comparing the residuals in Column 5 (14 June 2014 / Javad Triumph-VS / S.D. of DD CP residuals) with the residuals in Column 7 (23 July 2014 / Javad Triumph-VS / S.D. of DD CP residuals), it can be seen for a receiver (Javad Triumph or Septentrio NV), the standard deviations of DD CP residuals between the two days (for each signal) are close, especially when there are enough satellites available for analysis. The Javad and Septentrio receivers generate $\mathrm{CP}$ measurements from different signal components when tracking some new signals (L2C and L5). The Septentrio NV receiver uses L2C(L) and L5(Q) while the Javad triumph receiver uses $\mathrm{L} 2 \mathrm{C}(\mathrm{M}+\mathrm{L})$ and $\mathrm{L} 5(\mathrm{I}+\mathrm{Q})$. Their tracking methods are not configurable by users, so it is not possible to compare the residuals of these new signals. The BDS residuals of the Septentrio datasets are always less than $1 \mathrm{~mm}$ if the signal transmitting satellites are from the same type of orbit such as GEO and IGSO, but the residuals are greater than $2 \mathrm{~mm}$ if two satellites in DD are from different types of orbits, while the residuals of Javad datasets are always above $2 \mathrm{~mm}$ for $\mathrm{B} 1$ and below $1 \mathrm{~mm}$ for B2. The results also show the noise of phase tracking of $\mathrm{B} 1$ signals in the Javad receiver is significantly higher than those of B2, while there is no big difference between B1 and B2 in the Septentrio receiver. 


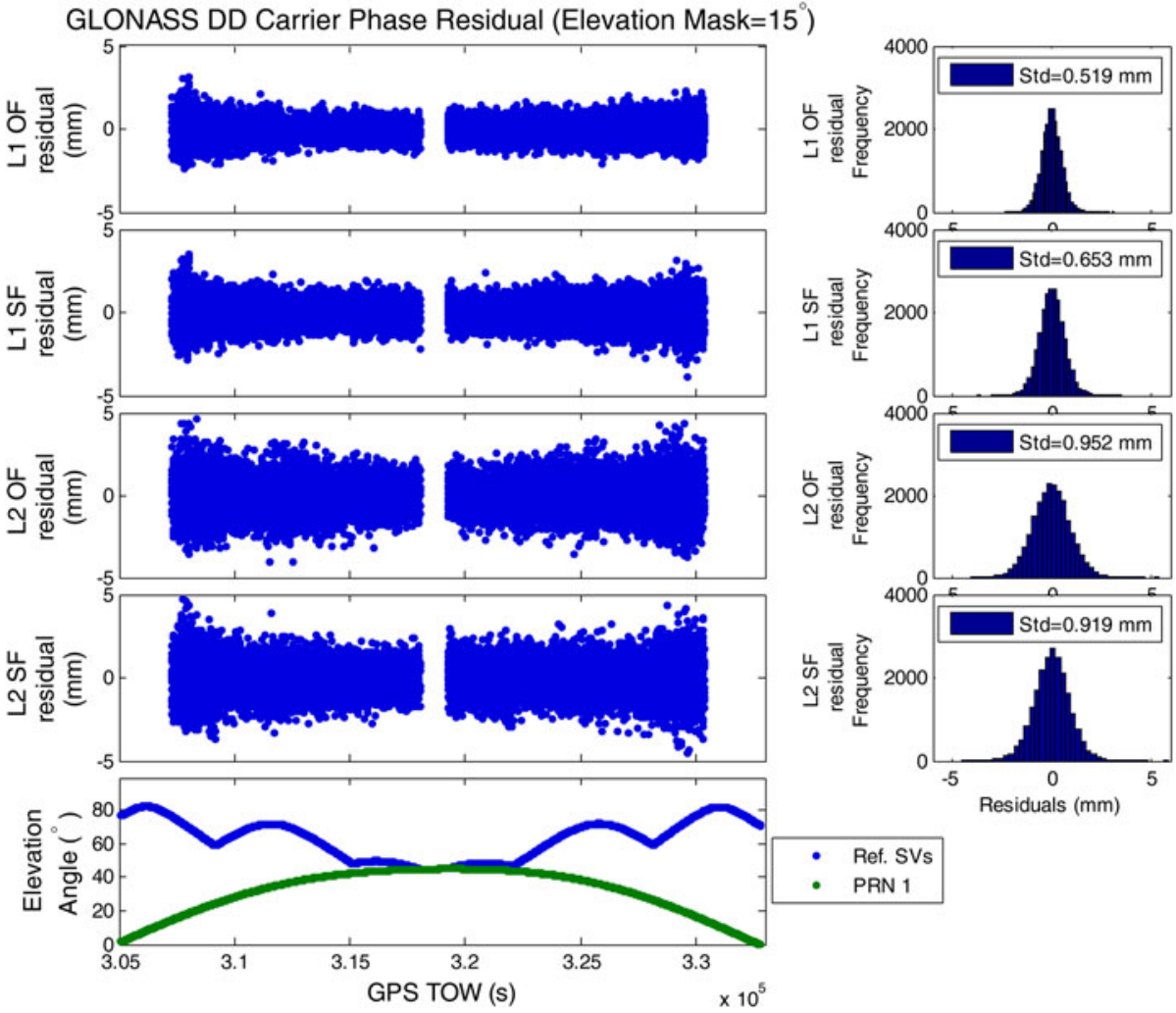

Figure 2. GLONASS DD CP residual for PRN01 in Test 1.

In summary, the DD CP residuals are between $0.5 \mathrm{~mm}$ and $1 \mathrm{~mm}$ for GPS and QZSS L1 C/A, L2C, and L5 signals, GLONASS L1 and L2 signals, and Galileo E1 signal. The DD CP residuals for GPS L1 P(Y) and L2 P(Y) signals, Galileo E5a and $\mathrm{E} 5 \mathrm{~b}$ are in the range between $1 \mathrm{~mm}$ and $2 \mathrm{~mm}$. The BDS B1I residuals are over $2 \mathrm{~mm}$ when DD is formed with two satellites in two orbit types, and the B2I residuals are less than $1 \mathrm{~mm}$ when DD is formed with two satellites in the same orbit type.

3.2. Ten-metre baseline test (Test 2) results

3.2.1. Single constellation positioning results. The fixed solution availability is the number of available epochs with fixed positioning solutions as a percentage of the total number of epochs. All the integer carrier phase ambiguities of observing satellites must be resolved correctly in fixed positioning solutions. The GNSS availabilities for Test 2 are summarised in Table 3. As shown in the table, GPS has very good fixed solution availabilities (over 99\%) with at least four satellites available during the 24-hour observation period in Datasets C and D. GLONASS has a similarly high fixed solution availability of $98 \cdot 58 \%$ in Dataset $\mathrm{C}$ but a low fixed solution availability of $84.31 \%$ in Dataset D with relatively fewer available satellites. The fixed solution availability for Galileo is currently low since there are currently only four satellites in orbit. No BDS result is presented in Dataset $\mathrm{C}$ because the receivers (Javad Sigma) used on 
Galileo DD Carrier Phase Residual (Elevation Mask $=15^{\circ}$ )
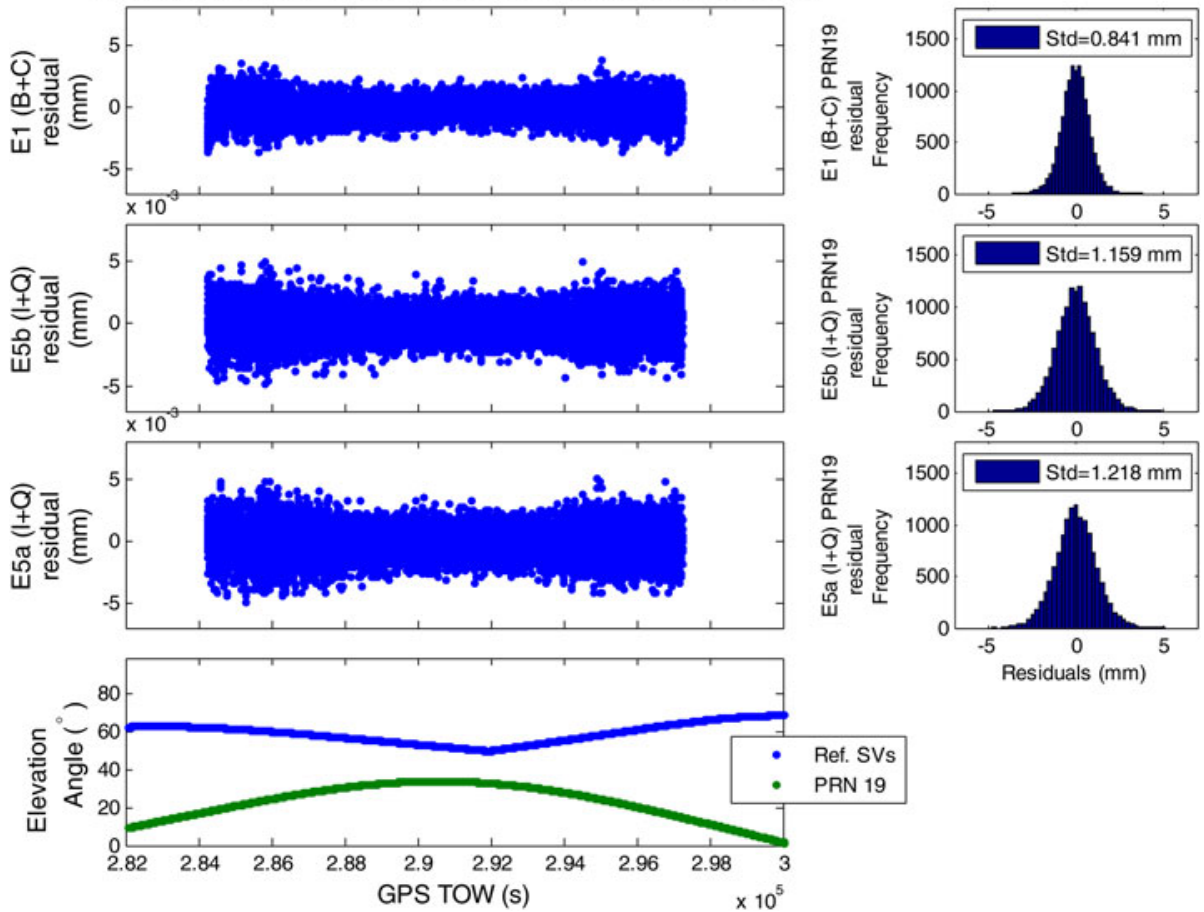

Figure 3. Galileo DD CP residual for PRN19 in Test 1.

Beidou DD Carrier Phase Residual (Elevation Mask $=15^{\circ}$ )
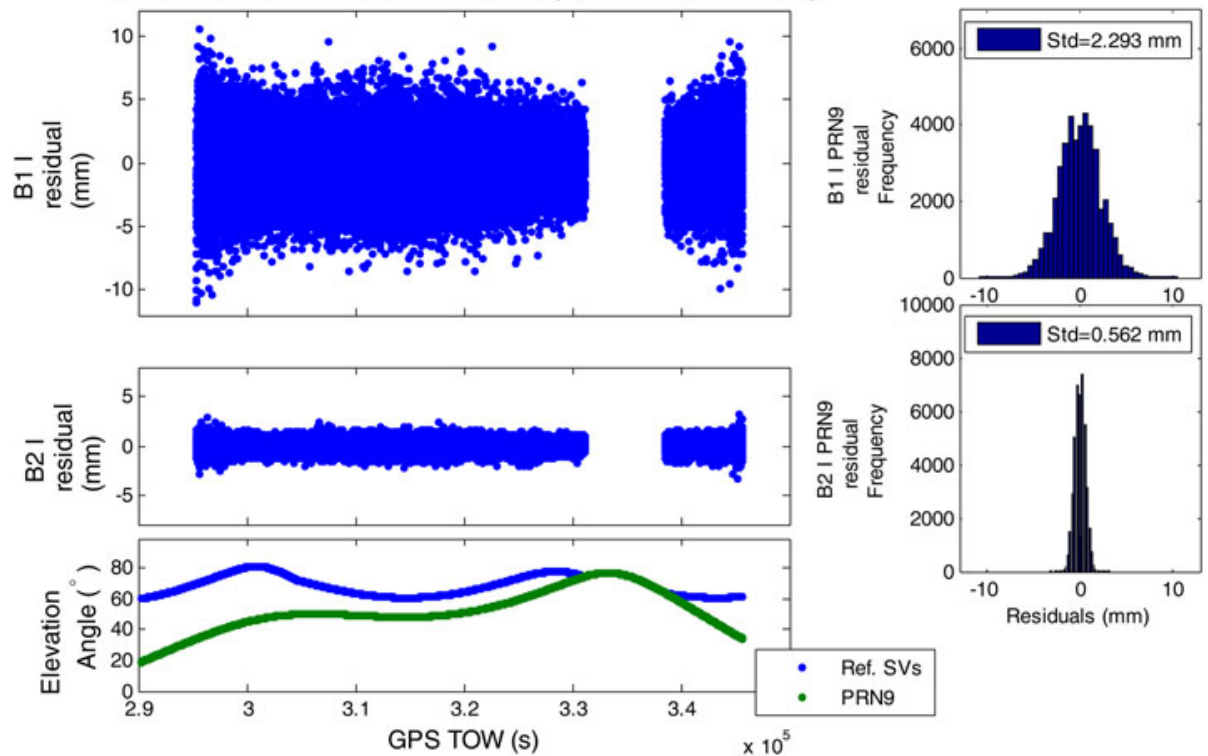

Figure 4. BDS DD CP residual for PRN09 in Test 1. 

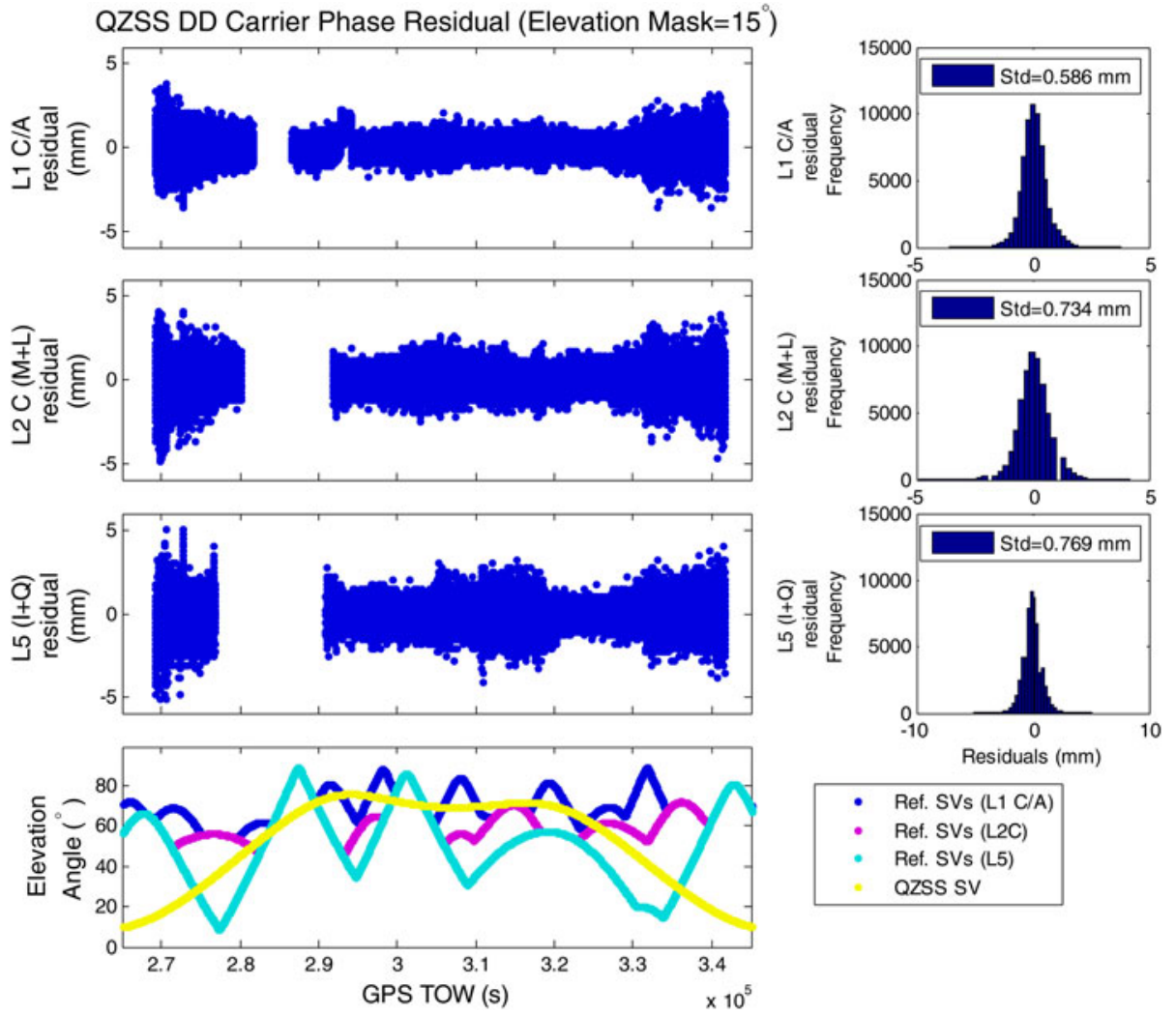

Figure 5. QZSS DD CP residual for satellite Michibiki in Test 1.

that day cannot receive BDS signals, but a high fixed solution availability of $99.99 \%$ for BDS can be observed in Dataset D with at least six available satellites.

Table 4 shows the precision and accuracy results of Test 2 with average Dilution of Precision (DOP) values computed. The precision and accuracy are associated with the DOP values in the datasets. In Dataset C, GPS has the best precision at the millimetre level and the best accuracy at the centimetre level. Galileo, with a maximum of four satellites during the tests, can still achieve centimetre level accuracy and precision in plane coordinates, but it has the worst accuracy in height. For GLONASS, in spite of its low Horizontal DOP (HDOP), it has the worst precision in height. In Dataset $\mathrm{D}$, the precisions and accuracies of GPS and GLONASS are relatively worse than those in Dataset $\mathrm{C}$ due to higher DOP value. Although BDS has higher DOPs than GPS, the precision and accuracy of BDS and GPS are close. This is because BDS has more observed satellites than GPS. Figure 6 shows the horizontal errors of the four GNSS systems in the two days. It shows GLONASS solutions have larger errors in Easting than Northing in the two days, but Galileo has larger error in Northing in the given dataset. GPS has an even spread of horizontal errors in Dataset $\mathrm{C}$, but larger Northing errors in Dataset D.

The elongated scatters in Figures 6(d) and 6(e) are due to poor satellite geometry. To take the scatters in Figure 6(d) as an example, Figure 7 shows the DOPs for a $15^{\circ}$ 
Table 2. Standard deviations (S.D.) of DD CP residuals using all available signals for all constellations in Test $1\left(\right.$ Elevation $\left.>15^{\circ}\right)$.

\begin{tabular}{|c|c|c|c|c|c|c|c|c|c|}
\hline \multirow{2}{*}{\multicolumn{4}{|c|}{$\begin{array}{l}\text { Test date } \\
\text { Receiver Type }\end{array}$}} & \multirow{2}{*}{\multicolumn{2}{|c|}{$\begin{array}{l}\text { 14-Jun-2014 } \\
\text { Javad Triumph-VS }\end{array}$}} & \multicolumn{4}{|c|}{ 23-Jul-2014 } \\
\hline & & & & & & \multicolumn{2}{|c|}{ Javad Triumph-VS } & \multicolumn{2}{|c|}{ Septentrio NV } \\
\hline \multicolumn{2}{|l|}{ GNSS } & $\begin{array}{l}\text { Freq. } \\
\text { Band }\end{array}$ & Signal & $\begin{array}{l}\text { No. } \\
\text { of } \\
\text { SV }\end{array}$ & $\begin{array}{l}\text { S.D. of DD } \\
\text { CP residuals } \\
(\mathrm{mm})\end{array}$ & $\begin{array}{l}\text { No. } \\
\text { of } \\
\text { SV }\end{array}$ & $\begin{array}{l}\text { S.D. of DD } \\
\text { CP residuals } \\
(\mathrm{mm})\end{array}$ & $\begin{array}{l}\text { No. } \\
\text { of } \\
\text { SV }\end{array}$ & $\begin{array}{l}\text { S.D. of DD } \\
\text { CP residual } \\
(\mathrm{mm})\end{array}$ \\
\hline \multirow{7}{*}{\multicolumn{2}{|c|}{$\overline{\text { GPS }}$}} & & $\mathrm{C} / \mathrm{A}$ & 32 & 0.570 & 31 & 0.641 & 31 & 0.707 \\
\hline & & $\mathrm{Ll}$ & $\mathrm{L} 1 \mathrm{P}(\mathrm{Y})$ & 32 & 1.656 & 31 & 1.682 & - & - \\
\hline & & & $\mathrm{L} 2 \mathrm{C}(\mathrm{L})$ & - & - & - & - & 13 & $1 \cdot 071$ \\
\hline & & $\mathrm{L} 2$ & $\mathrm{~L} 2 \mathrm{C}(\mathrm{M}+\mathrm{L})$ & 13 & 0.909 & 13 & 0.882 & - & - \\
\hline & & & $\mathrm{L} 2 \mathrm{P}(\mathrm{Y})$ & 32 & 2.023 & 31 & 2.053 & 31 & $1 \cdot 172$ \\
\hline & & & $\mathrm{Q}$ & - & - & - & - & 6 & 0.685 \\
\hline & & L5 & $\mathrm{I}+\mathrm{Q}$ & 4 & 1.008 & 6 & 0.939 & - & - \\
\hline \multirow{4}{*}{\multicolumn{2}{|c|}{ GLONASS }} & & $\mathrm{L} 1 \mathrm{C}$ & 20 & 0.572 & 24 & $0 \cdot 600$ & 24 & 1.001 \\
\hline & & $\mathrm{LI}$ & L1P & 20 & 0.718 & 24 & 0.752 & - & - \\
\hline & & & L2C & 20 & $0 \cdot 854$ & 24 & $0 \cdot 875$ & 24 & $1 \cdot 398$ \\
\hline & & $\mathrm{L} 2$ & $\mathrm{~L} 2 \mathrm{P}$ & 20 & $0 \cdot 880$ & 24 & 0.889 & - & - \\
\hline \multirow{4}{*}{\multicolumn{2}{|c|}{ Galileo }} & E1 & $\mathrm{C}$ & 3 & 0.679 & 3 & 0.769 & 3 & 0.938 \\
\hline & & & Q & - & - & - & - & 3 & $1 \cdot 161$ \\
\hline & & E5a & $\mathrm{I}+\mathrm{Q}$ & 3 & 0.907 & 3 & $1 \cdot 202$ & - & - \\
\hline & & $\mathrm{E} 5 \mathrm{~b}$ & $\mathrm{I}+\mathrm{Q}$ & 3 & $0 \cdot 874$ & 3 & $1 \cdot 241$ & - & - \\
\hline \multirow[t]{8}{*}{ BDS } & GEO & & I & 3 & $2 \cdot 980$ & 3 & 2.998 & 3 & $0 \cdot 741$ \\
\hline & IGSO & & I & 5 & $2 \cdot 172$ & 5 & $2 \cdot 156$ & 5 & 0.676 \\
\hline & MEO & $\mathrm{B} 1$ & I & 4 & 2.078 & 2 & 2.885 & 0 & - \\
\hline & All & & I & 12 & $2 \cdot 382$ & 12 & $2 \cdot 421$ & 11 & $2 \cdot 100$ \\
\hline & GEO & & I & 3 & 0.781 & 3 & $0 \cdot 819$ & 3 & 0.633 \\
\hline & IGSO & & I & 5 & 0.564 & 5 & 0.571 & 5 & 0.589 \\
\hline & MEO & B2 & I & 4 & 0.478 & 2 & 0.568 & 0 & - \\
\hline & All & & I & 12 & 0.629 & 12 & $0 \cdot 680$ & 11 & $2 \cdot 090$ \\
\hline \multirow{5}{*}{\multicolumn{2}{|c|}{ QZSS }} & L1 & $\mathrm{C} / \mathrm{A}$ & 14 & 0.520 & 18 & 0.575 & 18 & 0.682 \\
\hline & & I2 & $\mathrm{L} 2 \mathrm{C}(\mathrm{L})$ & - & - & - & - & 10 & $1 \cdot 042$ \\
\hline & & L2 & $\mathrm{L} 2 \mathrm{C}(\mathrm{M}+\mathrm{L})$ & 11 & 0.753 & 12 & 0.712 & - & - \\
\hline & & & $\mathrm{Q}$ & - & - & - & - & 7 & $0 \cdot 712$ \\
\hline & & L5 & $\mathrm{I}+\mathrm{Q}$ & 5 & $0 \cdot 880$ & 7 & 0.731 & - & - \\
\hline
\end{tabular}

elevation mask, and solution errors in Easting, Northing, and height components in the time interval from $2: 30$ to $3: 20$. The number of tracked satellites decreased to five from about 3:00, the GDOP jumps from 3 to above 10. The geometry deteriorates until another satellite PRN10 rises at 3:10, and then the solution accuracy returns to a normal level.

3.2.2. Multi-constellation positioning results. Average DOPs, precision, accuracy, and fixed solution availability of different combinations of GNSS constellations for Test 2 are summarised in Table 5. The combinations are GPS + GLONASS (GR), GPS + Galileo (GE), GPS + BDS (GC), GPS + QZSS (GQ), and all available constellations (GREQ or GRCQ). Compared with single constellation results in Table 4, there are slight improvements in both precision and accuracy in Dataset $\mathrm{C}$ when combining other constellations with GPS. The precision has 
Table 3. The number of observed satellites and fixed solution availability of positioning with single constellations in Test 2.

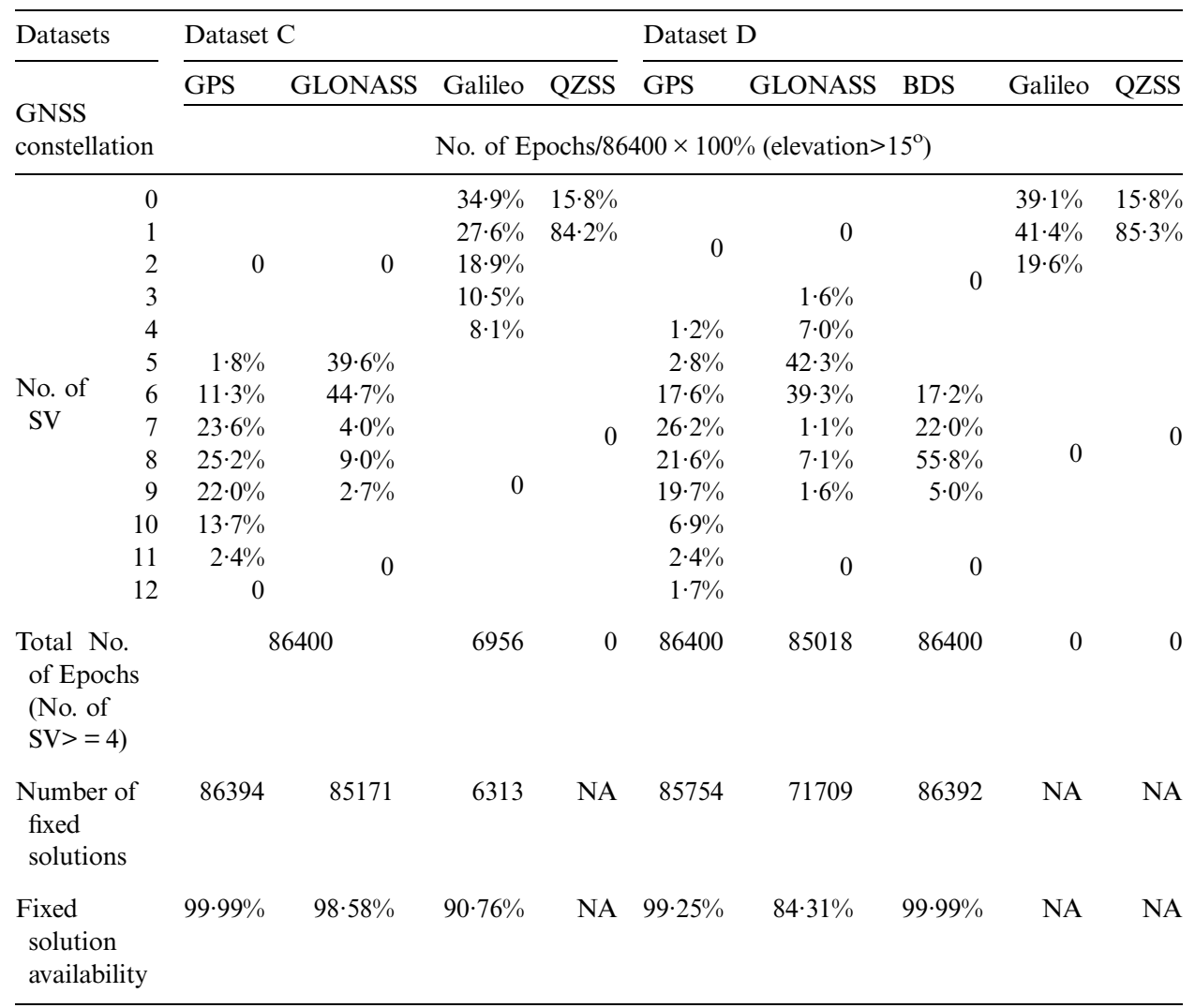

been improved to about $5 \mathrm{~mm}$ in both horizontal and height components with two GNSS constellations, while accuracy improvement is insignificant. The best precision and accuracy are the combination of GREQ. The precision and accuracy results in Dataset D are close to those in Dataset C, except that GQ shows a slightly worse precision and accuracy than those of using GPS alone. This phenomenon has also been observed by Lau et al. (2015) as mentioned in Section 1, and it is also observed in the $7 \mathrm{~km}$ baseline test, which will be presented and analysed in Section 3.3.2.

In summary, Test 2 shows that if the baseline length is very short, millimetre level precision and centimetre level accuracy can usually be achieved with the fixed solution availability of over $90 \%$ in a good environment (CP residuals shown in Appendix A show it is a low multipath contaminated environment). The fixed solution availability can be improved to almost $100 \%$ when adding another constellation to GPS, but the precision and accuracy improvements are insignificant compared with using GPS alone. It can also be observed that using all constellations GREQ or GRCQ does not give $100 \%$ fixed solution availability, this phenomenon is more obvious in Test 3, and it will be discussed in Section 3.3.2. 
Table 4. Average DOPs, precision, accuracy of positioning with single constellations in Test 2.

\begin{tabular}{|c|c|c|c|c|c|c|c|}
\hline \multirow{2}{*}{$\frac{\text { Datasets }}{\text { GNSS constellation }}$} & & \multicolumn{3}{|c|}{ Dataset C } & \multicolumn{3}{|c|}{ Datasets D } \\
\hline & & GPS & GLONASS & Galileo & GPS & GLONASS & $\mathrm{BDS}$ \\
\hline \multirow[t]{4}{*}{ Average DOP } & GDOP & $2 \cdot 7$ & $3 \cdot 8$ & $4 \cdot 0$ & $3 \cdot 1$ & $4 \cdot 7$ & $5 \cdot 0$ \\
\hline & PDOP & $2 \cdot 3$ & $3 \cdot 4$ & $3 \cdot 5$ & $2 \cdot 6$ & $4 \cdot 2$ & $4 \cdot 0$ \\
\hline & HDOP & $1 \cdot 1$ & $1 \cdot 6$ & $2 \cdot 0$ & $1 \cdot 3$ & 1.9 & $1 \cdot 7$ \\
\hline & VDOP & $2 \cdot 0$ & $3 \cdot 0$ & $2 \cdot 9$ & $2 \cdot 3$ & 3.9 & $3 \cdot 6$ \\
\hline \multirow{4}{*}{ Precision S.D. (mm) } & E & $2 \cdot 0$ & $3 \cdot 5$ & $3 \cdot 3$ & $2 \cdot 4$ & $6 \cdot 6$ & $2 \cdot 6$ \\
\hline & $\mathrm{N}$ & $2 \cdot 2$ & $2 \cdot 2$ & $5 \cdot 1$ & $4 \cdot 1$ & $2 \cdot 6$ & $2 \cdot 5$ \\
\hline & $\mathrm{U}$ & 5.9 & $27 \cdot 7$ & $8 \cdot 3$ & $7 \cdot 3$ & $21 \cdot 5$ & 11.9 \\
\hline & $2 \mathrm{D}$ & $5 \cdot 9$ & $8 \cdot 3$ & $12 \cdot 1$ & $9 \cdot 5$ & $14 \cdot 2$ & $7 \cdot 2$ \\
\hline \multirow[t]{4}{*}{ Accuracy RMS error (mm) } & E & $2 \cdot 6$ & $3 \cdot 9$ & $3 \cdot 7$ & $2 \cdot 9$ & $7 \cdot 1$ & $3 \cdot 2$ \\
\hline & $\mathrm{N}$ & 6.9 & 6.9 & $7 \cdot 2$ & 7 & $6 \cdot 1$ & $7 \cdot 6$ \\
\hline & $\mathrm{U}$ & $33 \cdot 7$ & $42 \cdot 1$ & $321 \cdot 0$ & 34 & $39 \cdot 9$ & $35 \cdot 1$ \\
\hline & $2 \mathrm{D}$ & $14 \cdot 7$ & $15 \cdot 9$ & $16 \cdot 2$ & $15 \cdot 2$ & $18 \cdot 7$ & $16 \cdot 5$ \\
\hline
\end{tabular}

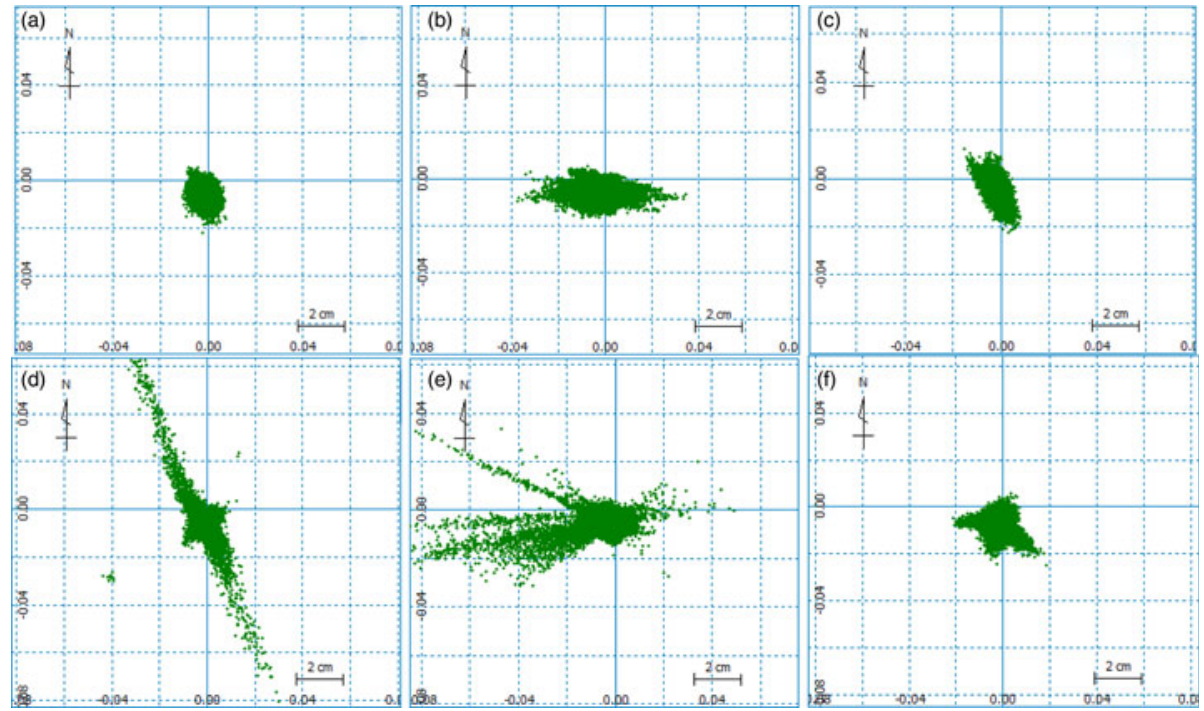

Figure 6. Error distribution in the horizontal plane of GPS (a), GLONASS (b), Galileo (c) of Dataset C, and GPS (d), GLONASS (e), BDS (f) of Dataset D.

\section{3. $7 \mathrm{~km}$ baseline test (Test 3 ) results}

3.3.1. Single constellation positioning results. The GNSS availabilities in Test 3 using Javad and Septentrio receivers are summarised in Tables 6 and 7, respectively. Since there is only one Galileo satellite observed during the test, the Galileo data is excluded in the data processing because RTKLIB cannot perform a DD observation with mixed GNSS constellations. From the comparison of the Tests 2 and 3 with Javad datasets, the fixed solution availabilities of GPS and GLONASS show more than about $2 \%$ and $10 \%$ reductions, respectively (see the last row, Columns 2 and 3 

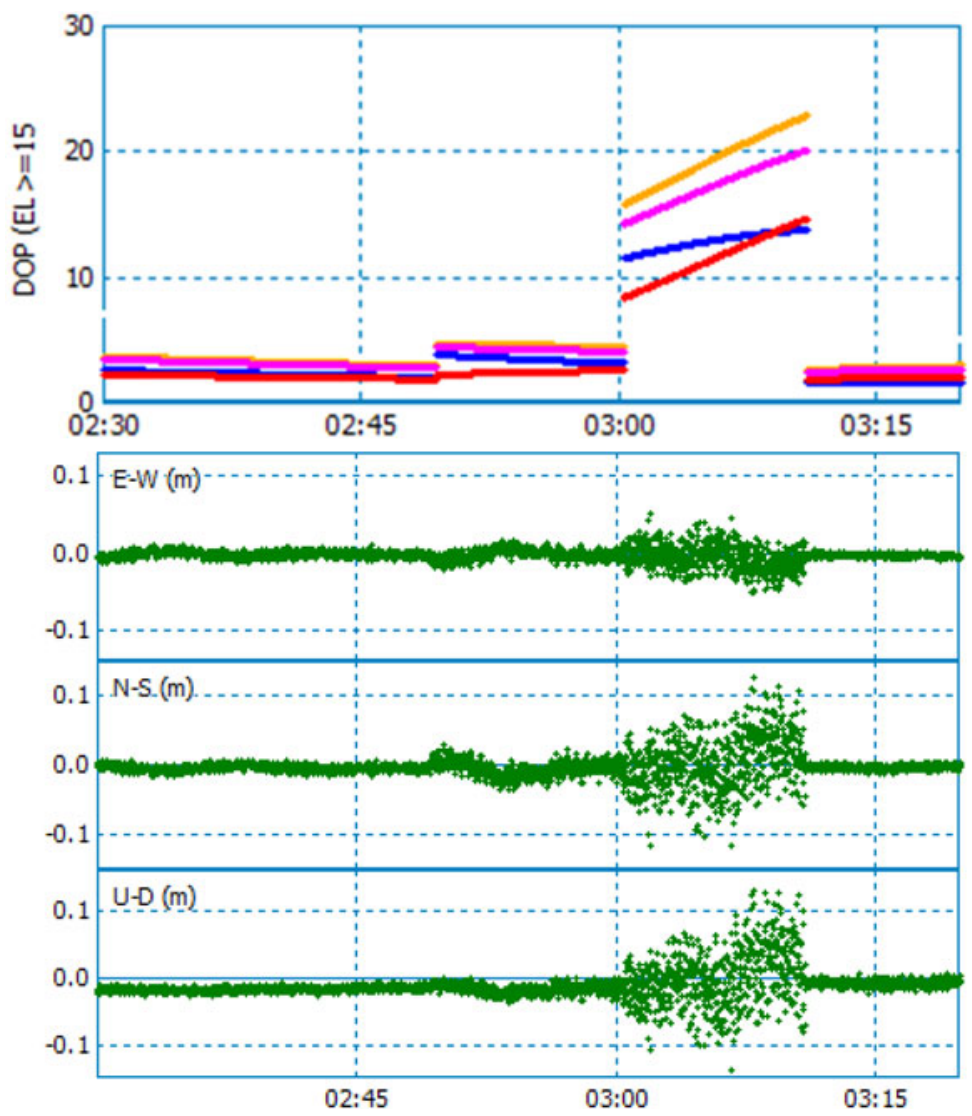

Figure 7. Geometric DOP (GDOP), Position DOP (PDOP), Horizontal DOP (HDOP), and Vertical DOP (VDOP) (represented with yellow, pink, blue, and red lines, respectively) for a $15^{\circ}$ elevation mask, and solution errors in Easting, Northing, and height components.

of Tables 3 and 6). However, BDS has over 99\% fixed solution availability in the test with at least six satellites. Comparing Table 6 with Table 7, it can be seen that the fixed solution availabilities for the Javad datasets are normally higher than those for the Septentrio datasets. Observations from the Septentrio dataset result in more failed AR than those from the Javad dataset when processed by RTKLIB, especially for GLONASS data. This is possibly due to a patented technique used by Javad receivers for GLONASS inter-channel bias calibration (Javad GNSS, 2013). One of the pieces of evidence is that the Signal to Noise Ratios (SNR) of Javad datasets are higher than those of Septentrio datasets (when the same antenna is used via a splitter).

Tables 8 and 9 show the average DOPs, precision and accuracy results for Test 3 with Javad and Septentrio datasets. Opposite to the fixed solution availability, the Septentrio datasets have better precision and accuracy than the Javad datasets. This may indicate that the different signal tracking strategies of two models of receivers bring about different balances between accuracy and fixed solution availability. The precision and accuracy of the $7 \mathrm{~km}$ baseline test are at the centimetre level for all the GNSS constellations, and they are worse than the results in the $10 \mathrm{~m}$ baseline 
Table 5. Average DOPs, precision, accuracy of positioning, and fixed solution availability of four combinations of constellations in Test 2.

\begin{tabular}{|c|c|c|c|c|c|c|c|c|c|}
\hline \multirow{2}{*}{\multicolumn{2}{|c|}{$\begin{array}{l}\text { Datasets } \\
\text { GNSS constellation } \\
\text { combinations }\end{array}$}} & \multicolumn{4}{|c|}{ Dataset C } & \multicolumn{4}{|c|}{ Dataset D } \\
\hline & & GR & GE & GQ & GREQ & GR & $\mathrm{GC}$ & GQ & GRCQ \\
\hline \multirow{4}{*}{$\begin{array}{l}\text { Average } \\
\text { DOP }\end{array}$} & GDOP & 1.9 & $2 \cdot 5$ & $2 \cdot 5$ & $1 \cdot 8$ & $2 \cdot 0$ & $2 \cdot 0$ & $2 \cdot 7$ & 1.6 \\
\hline & PDOP & 1.6 & $2 \cdot 1$ & $2 \cdot 1$ & 1.6 & $1 \cdot 7$ & 1.7 & $2 \cdot 3$ & $1 \cdot 3$ \\
\hline & HDOP & $0 \cdot 8$ & $1 \cdot 0$ & $1 \cdot 1$ & $0 \cdot 7$ & $0 \cdot 8$ & $0 \cdot 8$ & $1 \cdot 2$ & $0 \cdot 6$ \\
\hline & VDOP & $1 \cdot 4$ & 1.9 & $1 \cdot 8$ & $1 \cdot 4$ & $1 \cdot 5$ & $1 \cdot 5$ & $2 \cdot 0$ & $1 \cdot 2$ \\
\hline \multirow{4}{*}{$\begin{array}{l}\text { Precision } \\
\text { S.D. }(\mathrm{mm})\end{array}$} & E & 1.6 & $1 \cdot 8$ & 1.9 & $1 \cdot 6$ & 1.5 & $1 \cdot 4$ & $2 \cdot 7$ & $1 \cdot 6$ \\
\hline & $\mathrm{N}$ & $1 \cdot 6$ & $2 \cdot 1$ & $2 \cdot 0$ & 1.5 & 1.5 & $1 \cdot 3$ & $4 \cdot 0$ & $1 \cdot 6$ \\
\hline & $\mathrm{U}$ & $5 \cdot 0$ & $6 \cdot 0$ & $5 \cdot 5$ & $5 \cdot 2$ & $5 \cdot 3$ & $5 \cdot 2$ & $7 \cdot 2$ & $4 \cdot 7$ \\
\hline & $2 \mathrm{D}$ & $4 \cdot 5$ & $5 \cdot 5$ & $5 \cdot 5$ & $4 \cdot 4$ & $4 \cdot 2$ & $3 \cdot 8$ & $9 \cdot 7$ & $4 \cdot 5$ \\
\hline \multirow{4}{*}{$\begin{array}{l}\text { Accuracy RMS } \\
\text { error (mm) }\end{array}$} & $\mathrm{E}$ & $2 \cdot 3$ & $2 \cdot 4$ & $2 \cdot 6$ & $2 \cdot 3$ & $2 \cdot 2$ & $2 \cdot 1$ & $3 \cdot 1$ & $2 \cdot 3$ \\
\hline & $\mathrm{N}$ & $6 \cdot 8$ & $6 \cdot 8$ & 6.9 & $6 \cdot 7$ & $5 \cdot 9$ & $6 \cdot 4$ & $7 \cdot 0$ & $6 \cdot 4$ \\
\hline & $\mathrm{U}$ & 33.6 & $33 \cdot 3$ & $33 \cdot 4$ & $32 \cdot 9$ & $33 \cdot 7$ & $34 \cdot 0$ & $34 \cdot 0$ & $34 \cdot 1$ \\
\hline & $2 \mathrm{D}$ & $14 \cdot 4$ & $14 \cdot 4$ & $14 \cdot 7$ & $14 \cdot 2$ & $12 \cdot 6$ & $13 \cdot 5$ & $15 \cdot 3$ & $13 \cdot 6$ \\
\hline \multicolumn{2}{|l|}{$\begin{array}{l}\text { Fixed solution } \\
\text { availability }\end{array}$} & $99 \cdot 99 \%$ & $99 \cdot 97 \%$ & $100 \%$ & $99 \cdot 97 \%$ & $100 \cdot 00 \%$ & $99 \cdot 97 \%$ & $99 \cdot 46 \%$ & $99 \cdot 94 \%$ \\
\hline
\end{tabular}

test due to increased baseline length. The two-dimensional error spread of GPS, GLONASS, and BDS solutions are plotted in Figure 8. GPS has better accuracy and precision than the other two systems as shown in Tables 8 and 9. Although BDS has more satellites than GLONASS (as presented in Tables 6 and 7), it has higher DOP values. The poor satellite geometry of BDS is due to the fact that there are only three MEO satellites observed in the test, and its GEO and IGSO satellites are at relatively high elevation angles. Besides, the circled solutions in Figure 8(b) are likely caused by multipath propagation. They are not excluded in Table 8 because these solutions are statistically in the same population. Nevertheless, the precision (U, 2D) and accuracy (U, 2D) would be $(21.8 \mathrm{~mm}, 27.5 \mathrm{~mm})$ and $(22.6 \mathrm{~mm}$, $28.7 \mathrm{~mm}$ ), respectively, if the circled solutions in Figure $8(\mathrm{~b})$ are excluded.

3.3.2. Multi-constellation positioning results. Average DOPs, precision, accuracy, and fixed solution availability of five selected combinations of GNSS constellations for Test 3 are summarised in Tables 10 and 11. The selected combinations are GR, CR, GC, GQ, and all available GNSS constellations (GRCQ). Compared with the fixed solution availabilities of single GNSS constellations in Tables 6 and 7, the fixed solution availability for combined two or more GNSS is lower than those of individual GNSS constellations (except GQ). The fixed solutions availability dramatically falls when using GRCQ. This is probably because the processing software RTKLIB cannot perform a DD between two different systems (except GQ), and the increased GNSS constellations and satellites increase the chance of multipath errors and leads to failed AR at some epochs. Multipath is the major GNSS error in practical RTK positioning. Pseudorange multipath errors in L1 (MP1) and L2 (MP2) are estimated with linear combinations of the pseudorange and carrier phase observations (Estey and Meertens, 1999), examples of MP1 and MP2 plots in Appendix B (Figures B1 and B2) show that the rover site in the $7 \mathrm{~km}$ baseline test has significant multipath effect on GNSS signals. Clear sinusoidal patterns of multipath signature can be found in 
Table 6. The number of satellites and fixed solution availability of single constellations with Javad Triumph-VS receivers in Test 3.

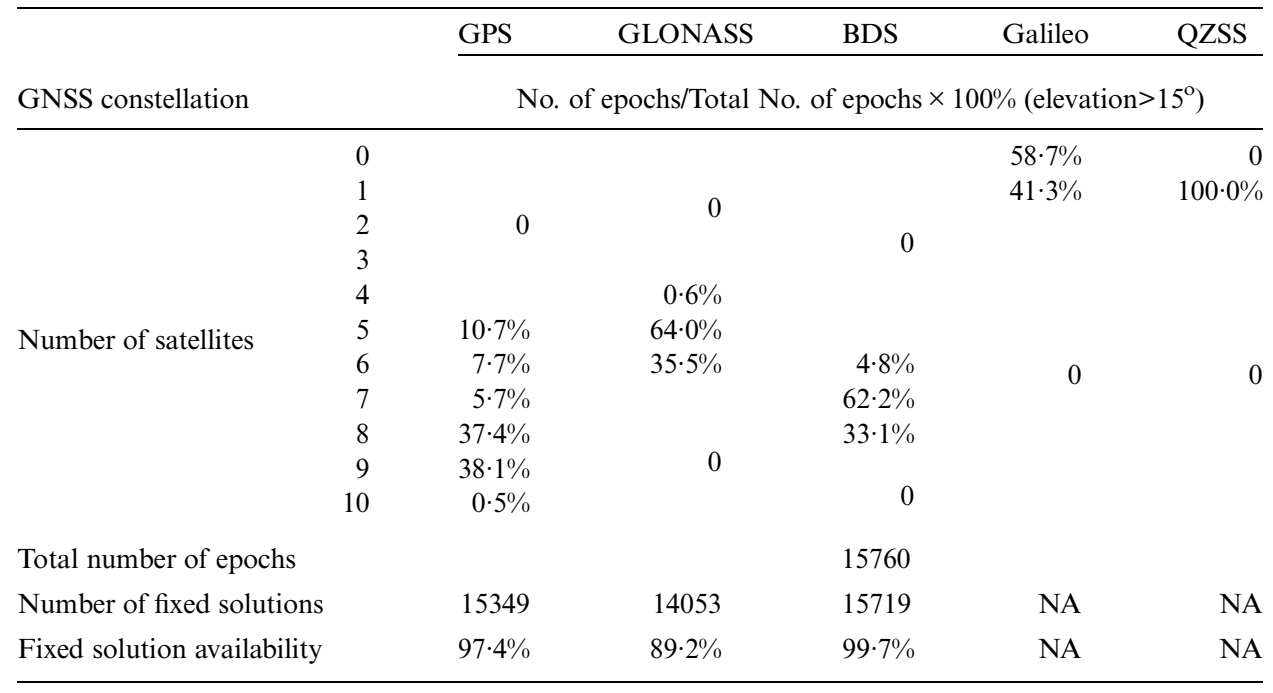

Table 7. The number of satellites and fixed solution availability of single constellations with Septentrio NV receivers in Test 3 .

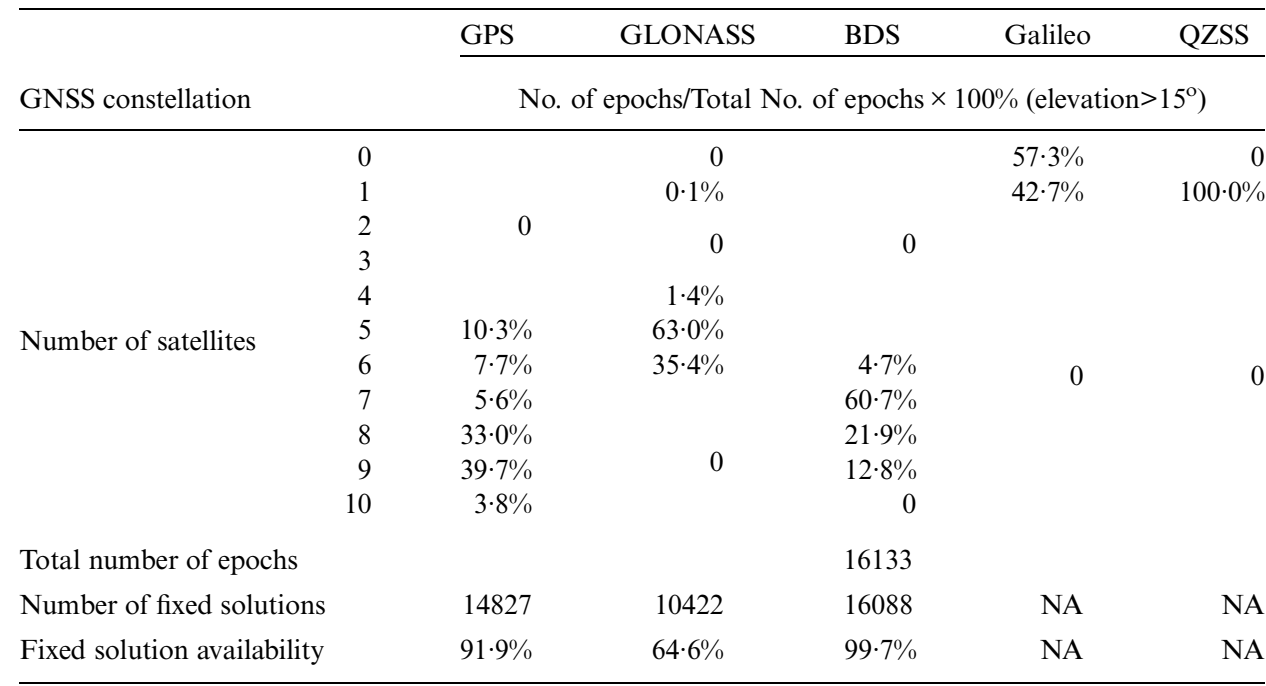

'True' error/residuals of some satellites with low elevation angles, examples are as shown in Appendix B (Figures B3 and B4).

In spite of decreased fixed solution availabilities of combining two or more GNSS constellations, Tables 10 and 11 show dual-constellations GR, CR and GC lead to obvious improvements in both accuracy and precision to about $2 \mathrm{~cm}$. Comparing the single GNSS results in Tables 8 and 9, combination GQ (the second last column) increases the accuracy and precision by about $3 \%$ in the horizontal component and $18 \%$ in the height for both Javad and Septentrio receivers. For other combinations 
Table 8. Average DOPs, precision, accuracy of single constellations with Javad Triumph-VS receiver in Test 3.

\begin{tabular}{llrrr}
\hline GNSS constellations & & GPS & GLONASS & BDS \\
\hline Average DOP & GDOP & $3 \cdot 2$ & $3 \cdot 2$ & $6 \cdot 5$ \\
& PDOP & $2 \cdot 7$ & $2 \cdot 7$ & $5 \cdot 1$ \\
& HDOP & $1 \cdot 3$ & $1 \cdot 6$ & $2 \cdot 1$ \\
& VDOP & $2 \cdot 4$ & $2 \cdot 3$ & $4 \cdot 6$ \\
Precision S.D. $(\mathrm{mm})$ & $\mathrm{E}$ & $8 \cdot 1$ & $23 \cdot 1$ & $9 \cdot 7$ \\
& $\mathrm{~N}$ & $11 \cdot 1$ & $11 \cdot 2$ & $13 \cdot 3$ \\
& $\mathrm{U}$ & $23 \cdot 7$ & $50 \cdot 4$ & $64 \cdot 8$ \\
& 2D & $27 \cdot 5$ & $51 \cdot 3$ & $32 \cdot 9$ \\
Accuracy RMS error $(\mathrm{mm})$ & $\mathrm{E}$ & $8 \cdot 1$ & $23 \cdot 2$ & $9 \cdot 7$ \\
& $\mathrm{~N}$ & $11 \cdot 7$ & $11 \cdot 3$ & $14 \cdot 7$ \\
& $\mathrm{U}$ & $23 \cdot 9$ & $37 \cdot 5$ & $64 \cdot 8$ \\
& 2D & $28 \cdot 5$ & $51 \cdot 6$ & $35 \cdot 2$ \\
\hline
\end{tabular}

Table 9. Average DOPs, precision, and accuracy of single constellations with Septentrio NV receiver in Test 3.

\begin{tabular}{llrrr}
\hline GNSS constellations & & GPS & GLONASS & BDS \\
\hline Average DOP & GDOP & $3 \cdot 1$ & $3 \cdot 2$ & $6 \cdot 2$ \\
& PDOP & $2 \cdot 7$ & $2 \cdot 7$ & $4 \cdot 9$ \\
& HDOP & $1 \cdot 2$ & $1 \cdot 7$ & $2 \cdot 0$ \\
Precision S.D. $(\mathrm{mm})$ & VDOP & $2 \cdot 3$ & $2 \cdot 3$ & $4 \cdot 4$ \\
& E & $8 \cdot 2$ & $11 \cdot 1$ & $9 \cdot 0$ \\
& N & $10 \cdot 1$ & $8 \cdot 3$ & $11 \cdot 8$ \\
Accuracy RMS error $(\mathrm{mm})$ & U & $21 \cdot 6$ & $24 \cdot 0$ & $37 \cdot 4$ \\
& 2D & $26 \cdot 0$ & $27 \cdot 7$ & $29 \cdot 7$ \\
& E & $8 \cdot 3$ & $11 \cdot 2$ & $9 \cdot 2$ \\
& N & $10 \cdot 4$ & $8 \cdot 6$ & $13 \cdot 2$ \\
& U & $21 \cdot 6$ & $25 \cdot 1$ & $38 \cdot 0$ \\
& 2D & $26 \cdot 6$ & $28 \cdot 2$ & $32 \cdot 2$ \\
\hline
\end{tabular}

GR, CR and GC, the accuracy and precision in horizontal and height components are generally improved when comparing with single GPS, GLONASS, and BDS constellations by over $20 \%, 30 \%$ and $30 \%$, respectively. However, there is an exception that combination CR in Septentrio dataset (the fourth column in Table 11) slightly deteriorates precision and accuracy in the height component compared to those of using GLONASS alone (the fourth column in Table 9). This is possibly caused by wrong AR due to the increased chance of multipath errors. It shows the impacts of combined GNSS systems compared with single GNSS solutions are not always beneficial.

4. CONCLUSIONS. This work has evaluated all the currently available GPS, GLONASS, Galileo, BDS and QZSS signals in a zero-baseline test, a $10 \mathrm{~m}$-baseline test, and a $7 \mathrm{~km}$ baseline test. The carrier phase residuals in the zero-baseline test are obtained by the double difference (DD) method. In the $10 \mathrm{~m}$ and $7 \mathrm{~km}$ baseline tests the data are processed by the open source software RTKLIB with a combination of forward and reverse solutions and elevation mask of $15^{\circ}$. 


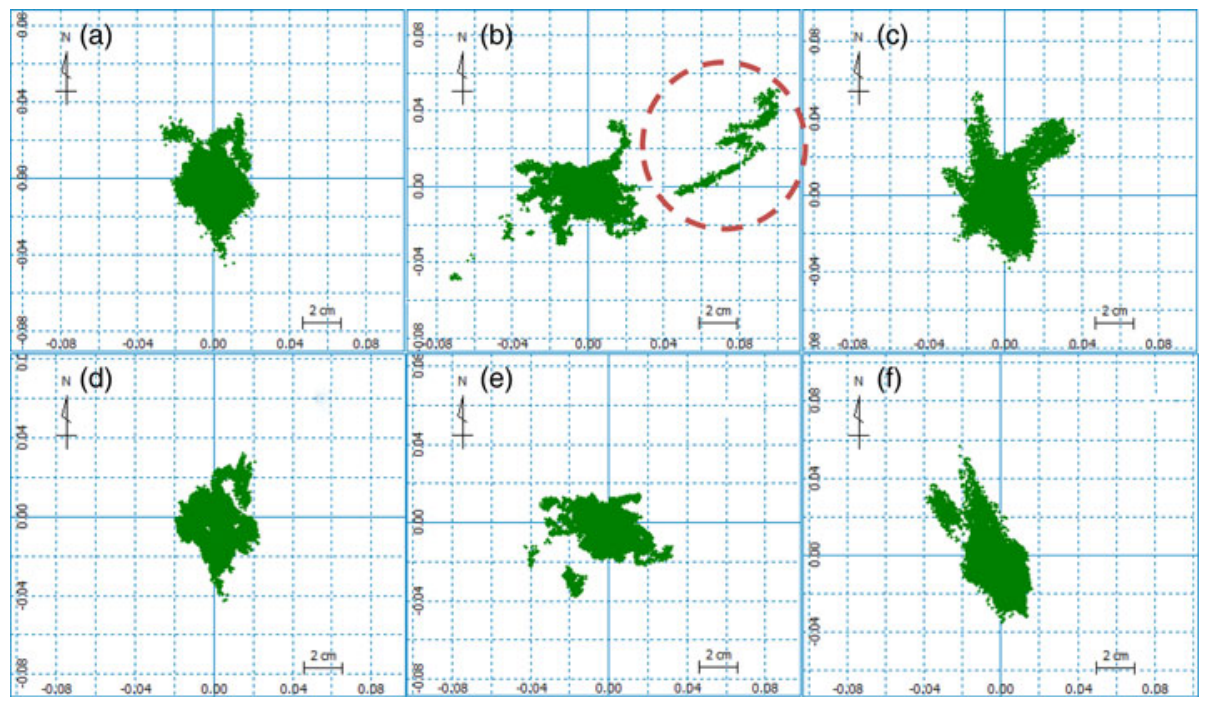

Figure 8. GPS (a,d), GLONASS (b,e), and BDS (c,f) positioning errors in horizontal plane with Javad Triumph $(\mathrm{a}, \mathrm{b}, \mathrm{c})$ and Septentrio NV $(\mathrm{d}, \mathrm{e}, \mathrm{f})$ receivers in Test 3.

Table 10. Average DOPs, precision, accuracy, and fixed solution availability of five combinations of constellations with Javad Triumph-VS receivers in Test 3.

\begin{tabular}{|c|c|c|c|c|c|c|}
\hline \multicolumn{2}{|c|}{ GNSS constellation combinations } & \multirow{2}{*}{$\frac{\mathrm{GR}}{1.9}$} & \multirow{2}{*}{$\frac{\mathrm{CR}}{2 \cdot 4}$} & \multirow{2}{*}{$\frac{\mathrm{GC}}{2 \cdot 1}$} & \multirow{2}{*}{$\begin{array}{l}\text { GQ } \\
2 \cdot 7\end{array}$} & \multirow{2}{*}{$\frac{\text { GRCQ }}{1 \cdot 6}$} \\
\hline Average DOP & GDOP & & & & & \\
\hline & PDOP & 1.6 & $2 \cdot 0$ & 1.8 & $2 \cdot 3$ & $1 \cdot 3$ \\
\hline & HDOP & $0 \cdot 8$ & $1 \cdot 0$ & $0 \cdot 8$ & $1 \cdot 2$ & $0 \cdot 7$ \\
\hline & VDOP & $1 \cdot 4$ & $1 \cdot 7$ & $1 \cdot 6$ & 1.9 & $1 \cdot 1$ \\
\hline \multirow[t]{4}{*}{ Precision S.D. (mm) } & $\mathrm{E}$ & $7 \cdot 6$ & $7 \cdot 7$ & $6 \cdot 4$ & $7 \cdot 9$ & $6 \cdot 5$ \\
\hline & $\mathrm{N}$ & $7 \cdot 7$ & $6 \cdot 2$ & $7 \cdot 8$ & $10 \cdot 6$ & $6 \cdot 5$ \\
\hline & $\mathrm{U}$ & $17 \cdot 0$ & $26 \cdot 3$ & $18 \cdot 6$ & $19 \cdot 2$ & $15 \cdot 8$ \\
\hline & $2 \mathrm{D}$ & $21 \cdot 6$ & $19 \cdot 8$ & $20 \cdot 2$ & $26 \cdot 4$ & $18 \cdot 4$ \\
\hline \multirow[t]{4}{*}{ Accuracy RMS error (mm) } & $\mathrm{E}$ & $7 \cdot 6$ & $8 \cdot 1$ & $6 \cdot 5$ & $7 \cdot 9$ & $6 \cdot 5$ \\
\hline & $\mathrm{N}$ & $8 \cdot 0$ & $8 \cdot 2$ & $9 \cdot 1$ & $11 \cdot 3$ & $7 \cdot 4$ \\
\hline & $\mathrm{U}$ & $18 \cdot 0$ & $26 \cdot 4$ & $18 \cdot 6$ & $19 \cdot 4$ & $15 \cdot 8$ \\
\hline & $2 \mathrm{D}$ & $22 \cdot 1$ & $23 \cdot 1$ & $22 \cdot 4$ & $27 \cdot 6$ & $19 \cdot 7$ \\
\hline Fixed solution availability & & $78 \cdot 0 \%$ & $91 \cdot 0 \%$ & $95 \cdot 7 \%$ & $97 \cdot 2 \%$ & $66 \cdot 3 \%$ \\
\hline
\end{tabular}

In the zero-baseline test the data is collected on two different days by two sets of Javad and Septentrio receivers. The DD carrier phase residuals of all existing signals have been assessed. Statistical results show the residuals vary with different signals and models of receivers, but they are similar from day to day. Also, the standard deviation of the residuals is reduced with an increase in the satellite elevation angle and vice versa, especially for GPS P(Y) signals. The DD carrier phase residuals for GPS and QZSS L1 C/A, L2, and L5 signals, GLONASS L1 and L2 signals, and Galileo E1 signal are between $0.5 \mathrm{~mm}$ and $1 \mathrm{~mm}$. The residuals for GPS L1P(Y) and L2P(Y) 
Table 11. Average DOPs, precision, accuracy, and fixed solution availability of five combinations of constellations with Septentrio NV receivers in Test 3.

\begin{tabular}{|c|c|c|c|c|c|c|}
\hline \multicolumn{2}{|c|}{ GNSS constellation combinations } & \multirow{2}{*}{$\frac{\mathrm{GR}}{1.9}$} & \multirow{2}{*}{$\frac{\mathrm{CR}}{2 \cdot 3}$} & \multirow{2}{*}{$\frac{\mathrm{GC}}{2 \cdot 0}$} & \multirow{2}{*}{$\frac{\mathrm{GQ}}{2 \cdot 6}$} & \multirow{2}{*}{$\begin{array}{r}\text { GRCQ } \\
1.5\end{array}$} \\
\hline Average DOP & GDOP & & & & & \\
\hline & PDOP & 1.6 & 1.9 & $1 \cdot 7$ & $2 \cdot 2$ & $1 \cdot 3$ \\
\hline & HDOP & $0 \cdot 8$ & 1.0 & 0.8 & $1 \cdot 2$ & $0 \cdot 7$ \\
\hline & VDOP & 1.4 & 1.7 & $1 \cdot 5$ & 1.9 & $1 \cdot 1$ \\
\hline \multirow[t]{4}{*}{ Precision S.D. (mm) } & $\mathrm{E}$ & $7 \cdot 3$ & $7 \cdot 2$ & $6 \cdot 2$ & $8 \cdot 1$ & $6 \cdot 7$ \\
\hline & $\mathrm{N}$ & $6 \cdot 1$ & $6 \cdot 0$ & $7 \cdot 7$ & $9 \cdot 7$ & $6 \cdot 7$ \\
\hline & $\mathrm{U}$ & $14 \cdot 3$ & $25 \cdot 3$ & $18 \cdot 6$ & $17 \cdot 7$ & $12 \cdot 9$ \\
\hline & $2 \mathrm{D}$ & $19 \cdot 0$ & $18 \cdot 7$ & $19 \cdot 8$ & $25 \cdot 3$ & $19 \cdot 0$ \\
\hline \multirow[t]{4}{*}{ Accuracy RMS error (mm) } & $\mathrm{E}$ & $7 \cdot 3$ & $7 \cdot 3$ & $6 \cdot 2$ & $8 \cdot 2$ & $6 \cdot 8$ \\
\hline & $\mathrm{N}$ & $6 \cdot 1$ & $7 \cdot 9$ & $8 \cdot 8$ & $10 \cdot 0$ & $7 \cdot 0$ \\
\hline & $\mathrm{U}$ & $15 \cdot 0$ & $25 \cdot 8$ & $18 \cdot 6$ & $17 \cdot 9$ & $14 \cdot 4$ \\
\hline & $2 \mathrm{D}$ & $19 \cdot 0$ & $21 \cdot 5$ & $21 \cdot 5$ & $25 \cdot 9$ & $19 \cdot 5$ \\
\hline Fixed solution availability & & $62 \cdot 1 \%$ & $88 \cdot 2 \%$ & $89 \cdot 4 \%$ & $92 \cdot 1 \%$ & $44 \cdot 5 \%$ \\
\hline
\end{tabular}

signals, Galileo E5a and E5b, are in the range between $1 \mathrm{~mm}$ and $2 \mathrm{~mm}$. The BDS B1I residuals are over $2 \mathrm{~mm}$ when DD is performed with two satellites in two orbit types, and the B2I residuals are less than $1 \mathrm{~mm}$ when DD is performed with two satellites in the same orbit type.

The $10 \mathrm{~m}$ baseline test shows that in ideal conditions (i.e., a low multipath contaminated environment), using a single GNSS constellation (GPS, GLONASS, Galileo, or $\mathrm{BDS}$ ) or their combinations can usually achieve millimetre-level precision and centimetre-level accuracy. The fixed solutions' availabilities are almost $100 \%$ except for Galileo, which is not at its Full Operational Capability. In the $7 \mathrm{~km}$ baseline test, both the positioning precision and accuracy reduce to the centimetre level. These results may provide surveyors with an idea of the achievable performance of the GNSS combinations in RTK surveying. A trade-off between fixed solution availability and accuracy has been observed in the datasets: using dual-constellations, such as GPS + GLONASS, GPS + BDS, GLONASS + BDS, and all available constellations (GPS + GLONASS + BDS + QZSS) can usually improve the precision and accuracy to about $2 \mathrm{~cm}$ in both plane and height components. However, using all available GNSS constellations can dramatically decrease the fixed solution availability, and using dual-constellations (e.g. GPS + QZSS in the $10 \mathrm{~m}$ baseline test and GLONASS + BDS in the $7 \mathrm{~km}$ baseline test) may slightly deteriorate precision and accuracy in some datasets. The reason is likely to be increased GNSS constellations and satellite numbers can introduce more multipath errors and lead to failed or wrong AR at some epochs.

Based on the results of this research, there are two directions of future work. Firstly, the results from the zero-baseline test are helpful in developing a stochastic model for multi-GNSS data processing. Proper weight can be assigned for carrier phase measurements according to the corresponding signal quality and satellite elevation angle. The second direction, from the observed trade-off between fixed solution availability and accuracy in Test 3, is to develop a better algorithm for satellite and signal selection to improve accuracy without compromising fix solution availability when using two or more GNSS constellations. 


\section{ACKNOWLEDGEMENTS}

This work was carried out at the International Doctoral Innovation Centre (IDIC). The authors acknowledge the financial support from Ningbo Education Bureau, Ningbo Science and Technology Bureau, China's MOST and The University of Nottingham. The work is also partially supported by EPSRC grant No EP/L015463/1.

\section{REFERENCES}

Ashjaee, J. and Lorenz, R. (1992). Precise GPS Surveying After Y-Code. Proceedings of the 5th International Technical Meeting of the Satellite Division of the Institute of Navigation (ION GPS 1992). Albuquerque, NM, September 1992, 657-659.

China Satellite Navigation Office. (2013). BDS Navigation Satellite System Signal in Space Interface Control Document Open Service Signal (Version 2.0). http://www.BDS.gov.cn/attach/2013/12/26/ 20131226b8a6182fa73a4ab3a5f107f762283712.pdf. Accessed 28 June 2014.

De Bakker, P.F., Tiberius, C., van der Marel, H. and van Bree, R.J.P. (2012). Short and zero baseline analysis of GPS L1 C/A, L5Q, GIOVE E1B, and E5aQ signals. GPS Solutions, 16(1), 53-64.

Estey, L.H., and Meertens, C. M. (1999). TEQC: the multi-purpose toolkit for GPS/GLONASS data. GPS Solutions, 3(1), 42-49.

Javad GNSS. (2013). TRIUMPH-VS Datasheet. http://www.javad.com/jgnss/products/receivers/triumph-vs. html. Accessed 8th July 2015.

Lau, L., Tateshita, H., and Sato, K. (2015). Impact of Multi-GNSS(GPS, GLONASS, and QZSS) on Positioning Accuracy and Multipath Errors in High-Precision Single-Epoch Solutions - A Case Study in Ningbo China. The Journal of Navigation, 68(5), 999-1017.

Montenbruck, O., Hauschild, A., Steigenberger, P., Hugentobler, U., Teunissen, P., and Nakamura, S. (2013). Initial Assessment of the COMPASS/BeiDou-2 Regional Navigation Satellite System. GPS Solutions, April, 2013, 17(2), 211-222.

Montenbruck, O., Hugentobler, U., Dach, R., Steigenberger, P., and Hauschild, A. (2012) Apparent Clock Variations of the Block IIF-1 (SVN62) GPS Satellite. GPS Solutions, 16(3), 303-313.

National Coordination Office for Space-Based Positioning, Navigation, and Timing. (2014). New Civil Signals. http://www.gps.gov/systems/gps/modernization/civilsignals/ Accessed 26 September 2014.

Odolinski, R., Odijk, D., and Teunissen, P.J.G. (2014). Combined GPS and BeiDou Instantaneous RTK Positioning. Navigation-Journal of the Institute Of Navigation, 62(2), 135-148.

Ong, R.B., Petovello, M.G., and Lachapelle, G. (2009). Assessment of GPS/GLONASS RTK Under Various Operational Conditions, Proceedings of ION GNSS 2009, the 22nd International Technical Meeting of the Satellite Division of The Institute of Navigation, Savannah, Georgia, September 22-25, 2009, 3297-3308.

Russian Institute of Space Device Engineering. (2008). GLONASS Interface Control Document Navigational Radiosignal in Bands L1, L2 (Edition 5.1) Moscow.

Seeber, G. (2003). Satellite Geodesy: Foundations, Methods, and Applications. $3^{\text {rd }}$ Ed. Walter De Gruyter, Berlin. 240-243.

Shi, C., Zhao, Q., Hu, Z., and Liu, J. (2013). Precise Relative Positioning using Real Tracking Data from COMPASS GEO and IGSO Satellites. GPS Solutions, 17(1) 103-119.

Steigenberger, P., Hugentobler, U. and Montenbruck, O. (2013). First Demonstration of Galileo-Only Positioning. GPS World, 24(2), 14-15.

Takac, F. (2009). GLONASS inter-frequency biases and ambiguity resolution, Inside GNSS, 2(4), 24-28.

Takasu, T. (2013). RTKLIB ver.2·4·2 Manual. http://www.rtklib.com/prog/manual_2.4.2.pdf. Accessed 26 September 2014.

Teunissen, P.J.G. (1993). Least-squares estimation of the integer GPS ambiguities. Invited lecture, Section IV Theory and Methodology, IAG General Meeting, Beijing, China. Also in: LGR series No.6, Delft Geodetic Computing Center, Delft University of Technology

Teunissen, P.J.G. (1995). The least-squares ambiguity decorrelation adjustment: a method for fast GPS integer ambiguity estimation. Journal of Geodesy, 70, 65-82.

Wang, J. (2000). An Approach to GLONASS Ambiguity Resolution. Journal of Geodesy, 74, 5, July 2000, $421-430$.

Wang, L., Groves, P.D., and Ziebart, M.K. (2012). Multi-Constellation GNSS Performance Evaluation for Urban Canyons Using Large Virtual Reality City Models. Journal of Navigation, 65, 459-476. 
APPENDIX A. FIGURE FOR GPS CP RESIDUALS IN TEST 2.
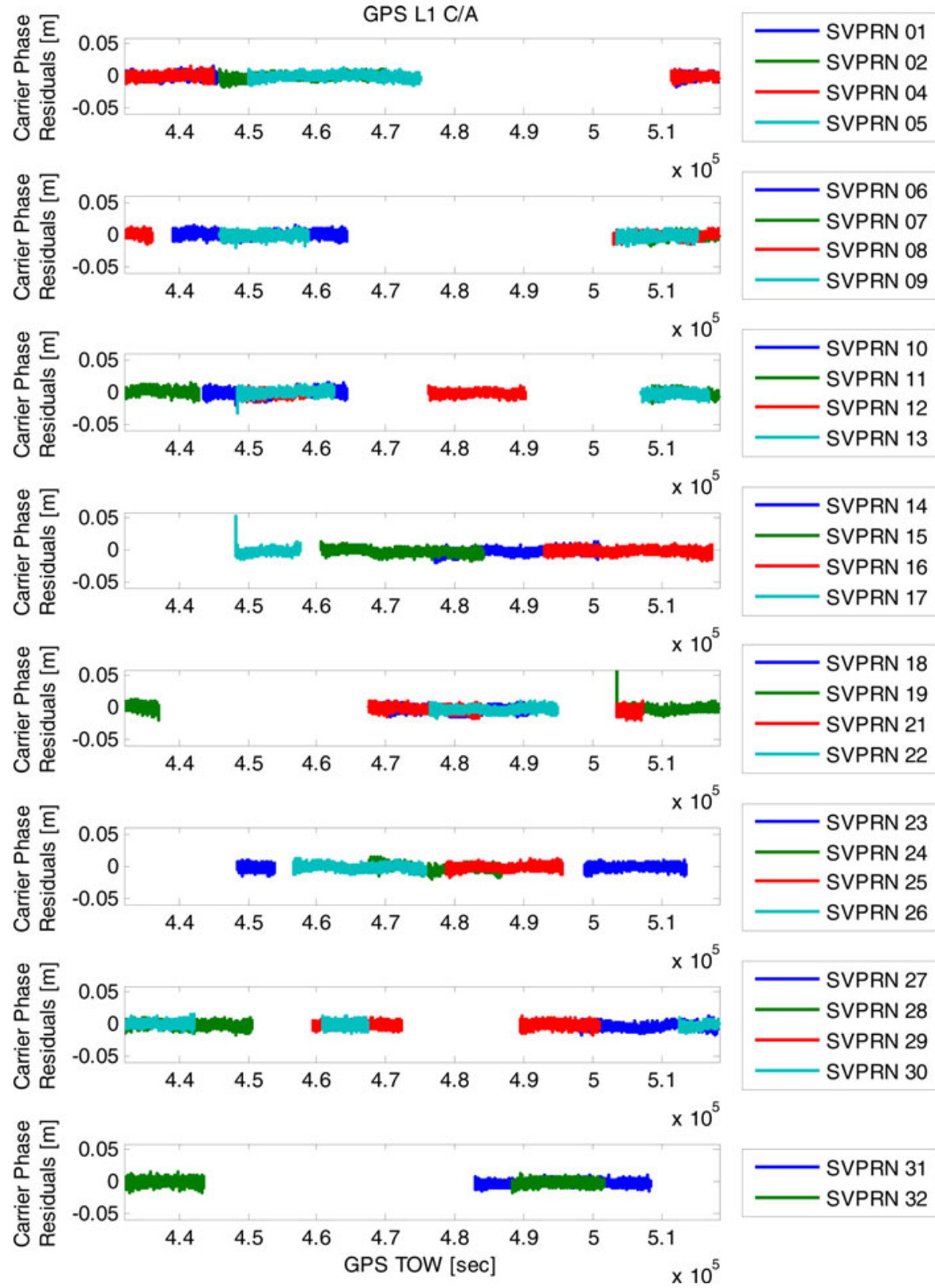

Figure A1. GPS L1 C/A DD carrier phase residuals (17-Oct-2014 dataset). 
APPENDIX B. FIGURE FOR MULTIPATH COMBINATIONS AND CP RESIDUALS IN TEST 3
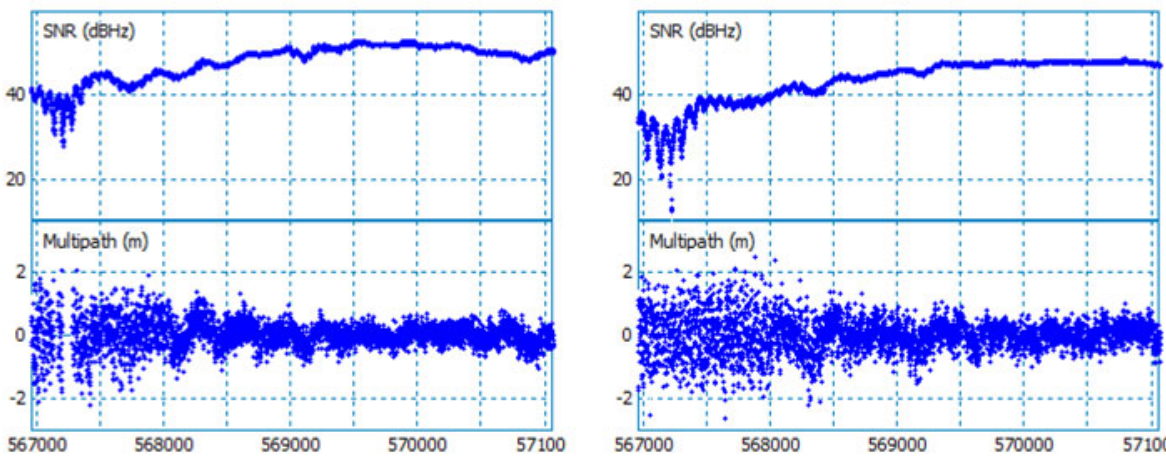

Figure B1. GPS L1 (left) and L2 (right) SNR and multipath combination of PRN15 in the $7 \mathrm{~km}$ baseline dataset.
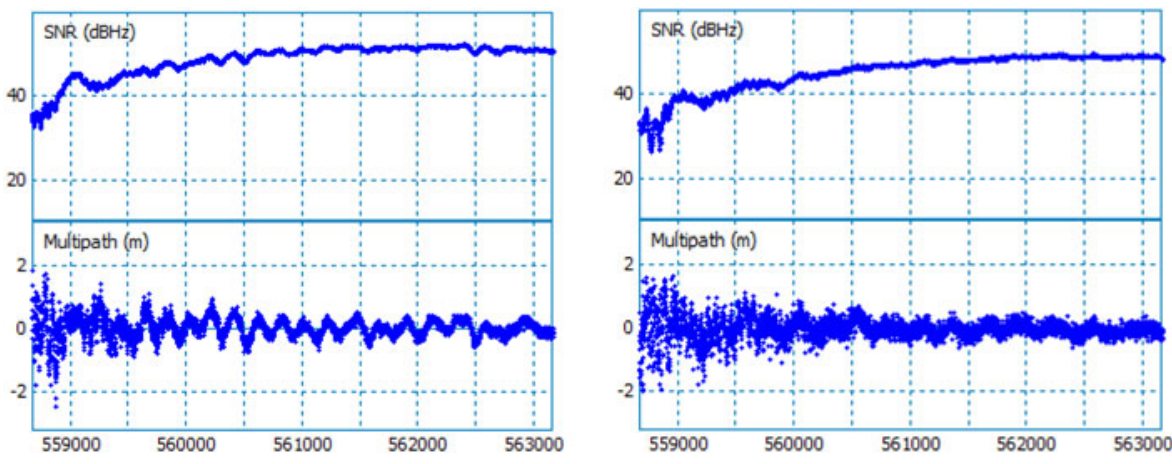

Figure B2. GLONASS L1 (left) and L2 (right) SNR and multipath combination of SV03 in the $7 \mathrm{~km}$ baseline dataset. 

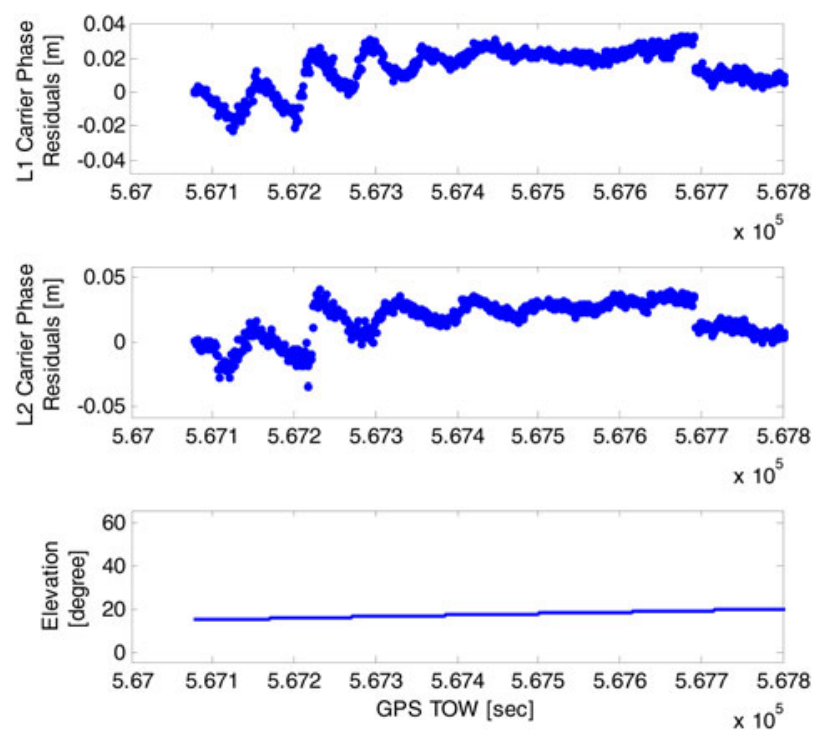

Figure B3. 'True' error/residuals in L1 C/A and L2P CP of GPS PRN15 in the $7 \mathrm{~km}$ baseline dataset.
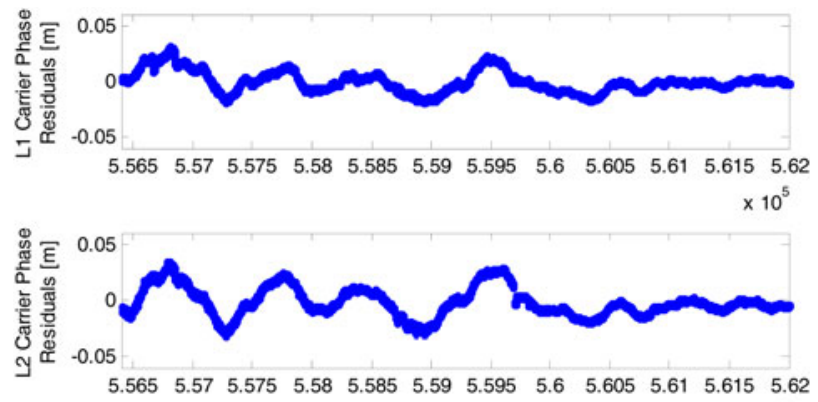

$\times 10^{5}$

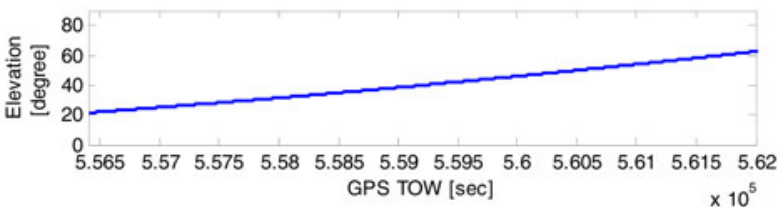

Figure B4. 'True' error/residuals in L1C and L2C of GLONASS SV17 in the $7 \mathrm{~km}$ baseline dataset. 